\title{
Experimental Study of Single-Lap, Hybrid Joints, Made of 3D Printed Polymer and Aluminium Adherends
}

\author{
Przemysław Golewski (D), Marek Nowicki *, Tomasz Sadowski (D) and Daniel Pietras
}

check for updates

Citation: Golewski, P.; Nowicki, M.; Sadowski, T.; Pietras, D. Experimental Study of Single-Lap, Hybrid Joints, Made of 3D Printed Polymer and Aluminium Adherends. Materials 2021, 14, 7705. https://doi.org/ $10.3390 /$ ma14247705

Academic Editor: Ricardo J. C. Carbas

Received: 22 November 2021 Accepted: 11 December 2021 Published: 13 December 2021

Publisher's Note: MDPI stays neutral with regard to jurisdictional claims in published maps and institutional affiliations.

Copyright: (C) 2021 by the authors. Licensee MDPI, Basel, Switzerland. This article is an open access article distributed under the terms and conditions of the Creative Commons Attribution (CC BY) license (https:/ / creativecommons.org/licenses/by/ $4.0 /)$.
Department of Solid Mechanics, Faculty of Civil Engineering and Architecture, Lublin University of Technology, Nadbystrzycka 38, 20-618 Lublin, Poland; p.golewski@pollub.pl (P.G.); t.sadowski@pollub.pl (T.S.); d.pietras@pollub.pl (D.P.)

* Correspondence: marek.nowicki@pollub.pl

\begin{abstract}
This paper presents the results of an experimental study into single-lap joints. One part of the joint was made as a 3D printed polymer and had cylindrical tenons, while the other part was made of an aluminium flat bar having mortises whose diameter and distribution corresponded to the polymer tenons. In addition to the mechanical joint, a layer of double-sided VHB (Very High Bond) adhesive tape was also placed in the lap, thus creating a hybrid joint. In total, 80 specimens were made, which were divided into four groups: A-specimens with one tenon of different diameters, B-specimens with different number of tenons of the same diameter, C—specimens characterised by multi-stage operation and $\mathrm{R}$-reference specimens, connected only by double-sided adhesive tape. The joints were subjected to uniaxial tensile tests. The force-displacement characteristics obtained and the energy required, up to the point of the failure of the joints, have been analysed in this paper. The four and six-stage joints designed can significantly increase the safety of the structures in which they will be used.
\end{abstract}

Keywords: hybrid joints; single lap joints; 3D printing

\section{Introduction}

The use of 3D printing is becoming increasingly popular, not only for the fabrication of mock-ups and prototypes, but also for industrial scale products. 3D printing technology facilitates production for multi-material products [1], reduces defects and lowers both production costs [2] and the need for repairs [3]. Considering the statistics, the Compound Annual Growth Rate (CAGR) for the next few years averages $23.5 \%$. This means that the market will double every three years. Such significant growth also results in the greater involvement of researchers to improve this technology. However, not all parts can be replaced by printed products, since they may not be cost-effective, hence the problem of joining them with other materials arises. There are many joining techniques such as riveting [4], welding, spot-welding [5], friction stir welding (FSW) [6], friction stir interlocking (FSI) [7,8] and clinching [9]. The authors in [7] used micro-texturing by ablative laser pre-treatment on the surface of an aluminium alloy. In this case, the polymer-aluminium bonding was done using the FSW method, which produced high strength. In the paper [10], the authors used the Injection Clinching Joining (ICJ) method in which a pre-formed polymeric tenon is melted and formed in the mortise of a metal part. This type of mechanical joint is free of clearance. A similar technique is presented in [11], but in this case an aluminium tenon, made by a printing technique on the surface of a thin-walled profile, is used. At present, the laser-assisted technique is also used for joining metal-printed polymer structures [12,13]. During this process, the polymer is melted under the influence of laser beam energy and penetrates the structure of the metal surface under the application of a specific joining pressure. The advantage of this type of solution is that there is no correlation between the surface roughness $\mathrm{Ra}$ and the shear strength of the joint. A similar technique is ultrasonic welding [14], which allows thermoplastic composites to be 
joined with aluminium alloys. In the work [15], the authors used a clinched metal-polymer type joint. Experimental studies were conducted by varying the main process parameters such as heating time, the temperature of the air and moulding pressure.

A common feature of these types of mechanical connections is that they invade the structure of the parts being joined. In many cases, they are also a source of concentrated stress. Therefore, another group of joints that can be used to connect polymer 3D prints are adhesive joints, either using liquid adhesives $[16,17]$, tapes [18] or dual-adhesive $[19,20]$. Their advantage is that the load is transferred over a considerable area and thus distribution of the stress, in the joined parts, is in many cases free of concentration.

Currently, the study of the adhesive bonding of polymer 3D prints has been carried out in many directions. The works [21,22] analysed the effect of surface topography on peel and shear strength. The surface topography can also be designed, for example, by introducing undulation [23]. When using adhesive joints, the thickness of the adhesive plays a large role. In the paper [24], three adhesive thicknesses were analysed: $0.2 \mathrm{~mm}, 0.3 \mathrm{~mm}$ and $0.4 \mathrm{~mm}$. It was shown that the $0.2 \mathrm{~mm}$ thickness was the best and led to higher mechanical performance and tensile strength compared to the other two. The bonding strength also depends on the adhesive used. When bonding polymer 3D prints, it is more beneficial to use cyanoacrylate adhesive than epoxy adhesive [25]. Surface wettability, which is another parameter, can be modified by sandblasting or by employing atmospheric plasma treatment; using the second, an increase of $200 \%$ in shear strength can be achieved [26].

In recent years, connections using double-sided adhesive tapes have received increasing attention [27-31]. In many cases, they allow traditional liquid adhesives or mechanical joints to be replaced. From a researcher's point of view, the soft and relatively thick (0.4-1.6 mm) layer of double-sided adhesive tape also comes with some challenges. The acrylic-based polymer used in VHB tapes is highly deformable, highly visco-elastic and very sensitive to temperature changes, hence the numerical modelling of this type of bond is difficult.

The simultaneous use of two techniques: mechanical and adhesive joints lead to a hybrid joint [32,33]. In this case, research is usually conducted using a single-lap scheme and various types of mechanical fasteners such as screws [34-36], embossing [37] and spot-welding [38].

To sum up, many techniques are used to join polymer 3D prints. Authors most often aim to increase their strength and often the energy used, up to the point of the failure of the joint, is also analysed. However, there is not much call to use the two simplest solutions: double-sided adhesive tape and mechanical connection of the "mortise and tenon" type. This type of hybrid solution is the subject of this paper. Its advantage is the rapidity with which the joints can be produced, since no adhesive curing time is needed and also, by properly selecting the ratio of the surface of the mechanical joint to the surface of the double-sided adhesive tape, it is possible to design the characteristics of the joint. In this paper, the results of the laboratory tests for innovative joints, with multi-stage characteristics, are also presented.

\section{Materials and Methodology}

Testing of the hybrid joints was performed using the popular and currently most widely used single-lap model. The dimensions of the joints, which are shown in Figures 1-3, were designed so that there would be no fracturing of the connected parts.

The hybrid joints were divided into 3 groups:

- group A-single-lap joints with one tenon having 5 different diameters " $\mathrm{D}$ ": $5 \mathrm{~mm}$, $8 \mathrm{~mm}, 11 \mathrm{~mm}, 14 \mathrm{~mm}$ and $19 \mathrm{~mm}$ (Figure 1),

- group B-joints with different numbers of tenons of the same diameter $\mathrm{D}=5 \mathrm{~mm}$ (Figure 2),

- group C-special joints, characterised by multi-stage operations with tenons of diameter $\mathrm{D}=5 \mathrm{~mm}$ (Figure 3 ). 
In addition, reference joints " $R$ " were made, using only double-sided adhesive tape, having the same dimensions as in Figure 1. In each case, 5 specimens were used per batch, hence the total number of specimens was 80 .

a)

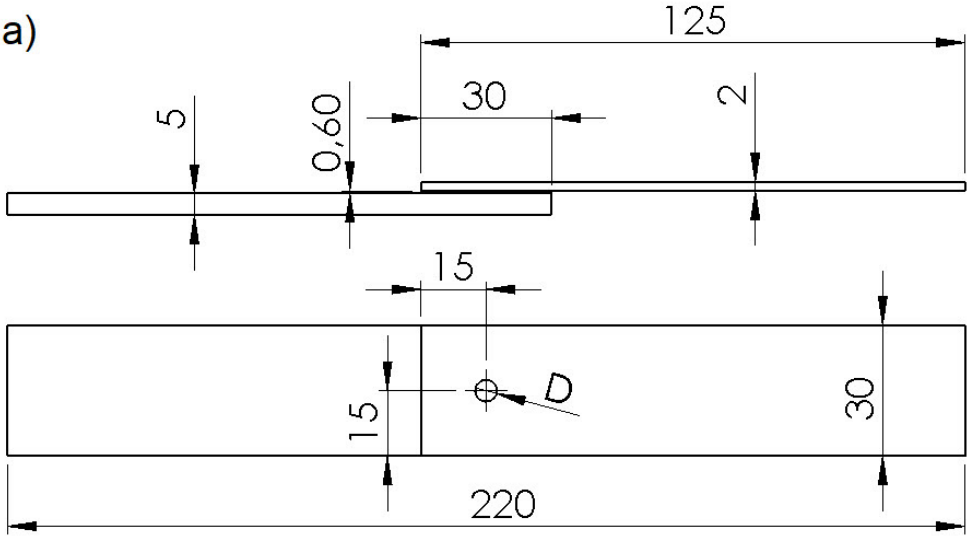

b)

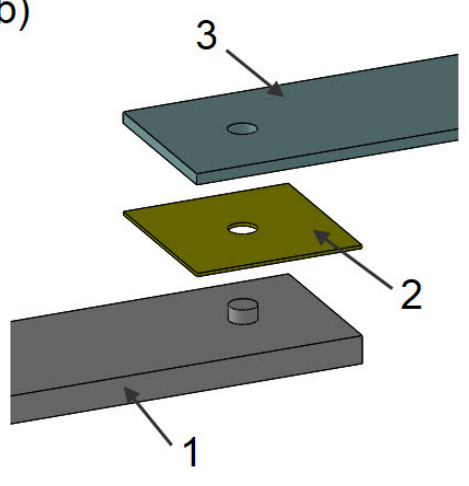

Figure 1. Joints with one tenon: (a) joint diagram; (b) perspective view (1-polymer lap, 2—double-sided adhesive tape, 3-aluminium lap).

(a)

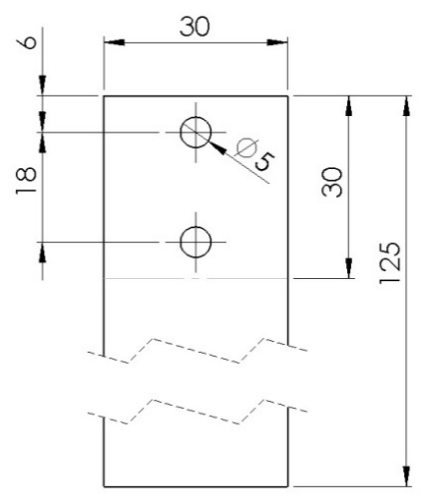

(d)

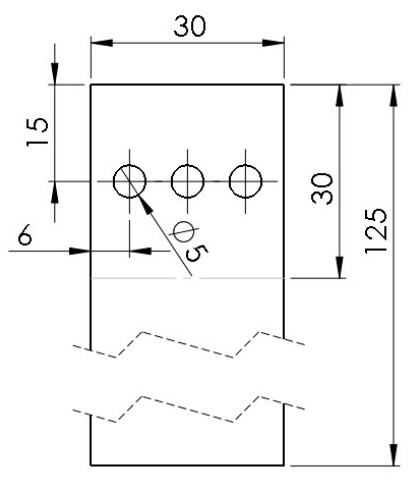

(b)

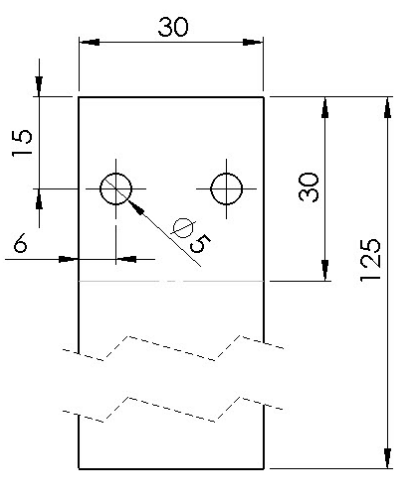

(e)

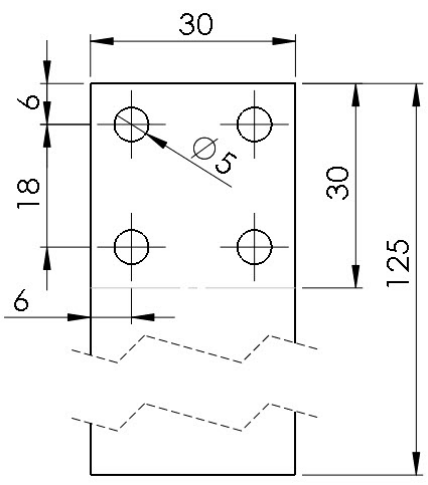

(c)

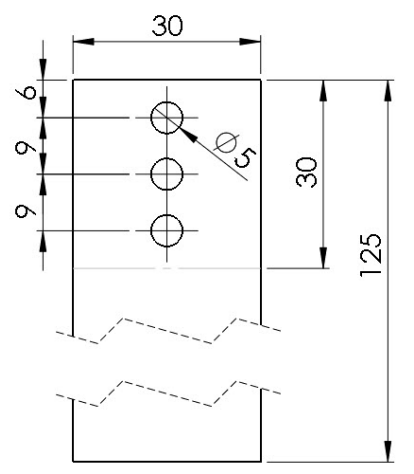

(f)

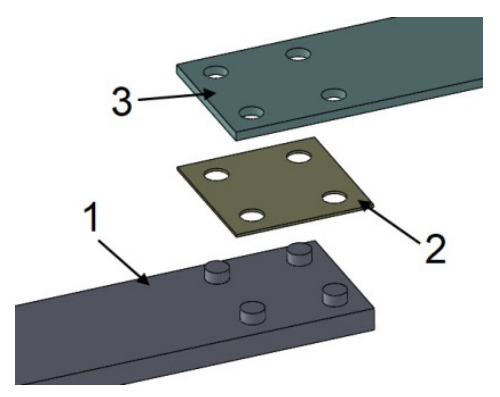

Figure 2. Types of joints with different numbers of tenons of the same diameter D = $5 \mathrm{~mm}$ : (a) model B1; (b) model B2; (c) model B3; (d) model B4; (e) model B5; (f) model B5 in perspective view (1-polymer lap, 2-double-sided adhesive tape, 3-aluminium lap). 
(a)

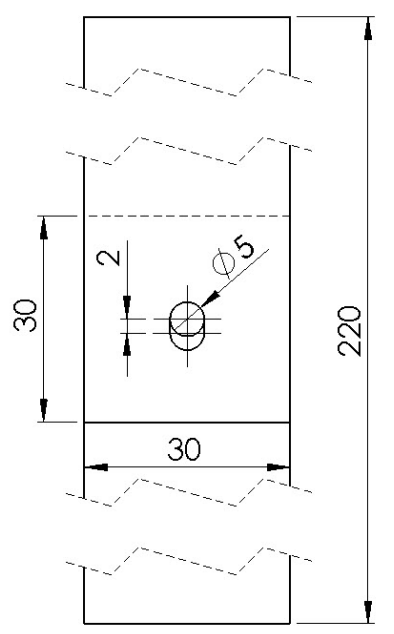

(d)

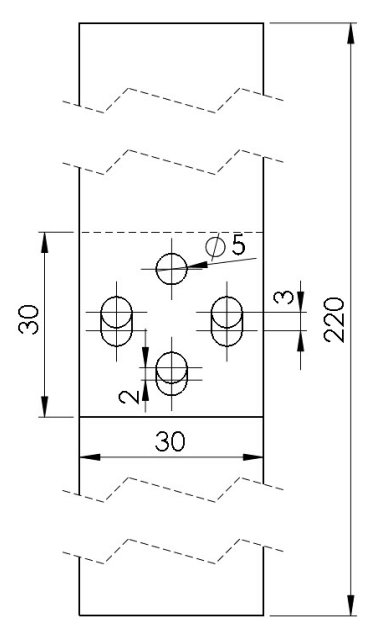

(b)

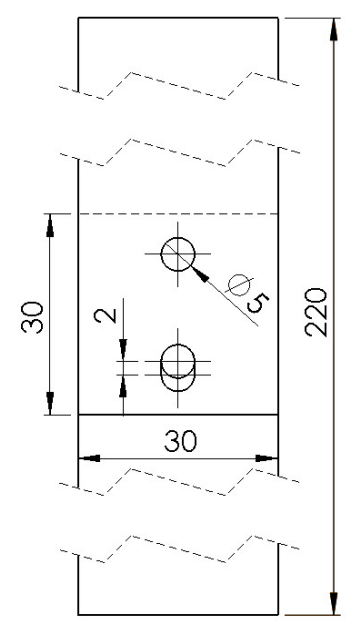

(e)

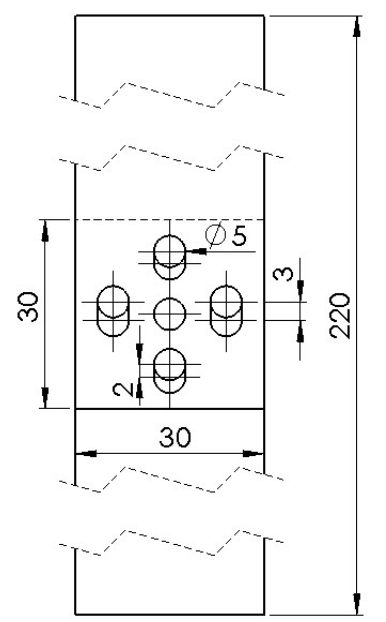

(c)

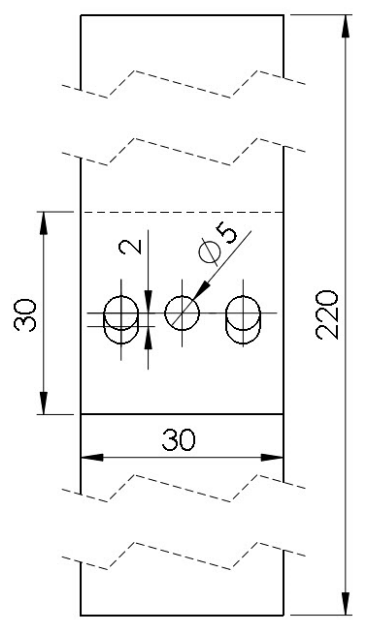

(f)

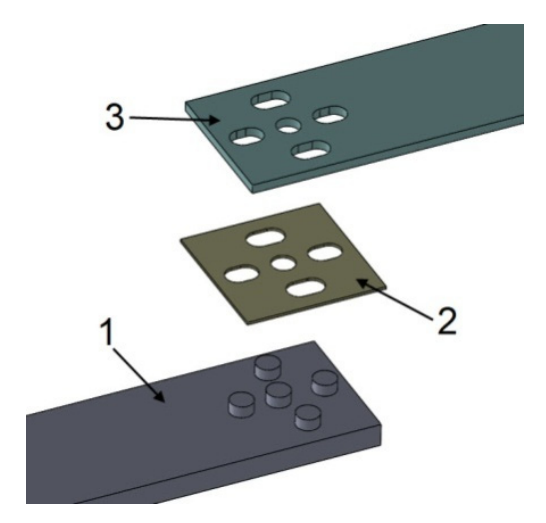

Figure 3. Special joints characterised by multi-stage operation using tenons of diameter $\mathrm{D}=5 \mathrm{~mm}$ : (a) model C1; (b) model C2; (c) model C3; (d) model C4; (e) model C5; (f) model C5 in perspective view (1-polymer lap, 2-double-sided adhesive tape, 3-aluminium lap).

3D prints of polymer laps, made of Z-ABS material including the tenons, were made on a Zortrax M300 printer. The print parameters and material data of the filament are shown in Table 1.

Although the tensile strength of the ABS material according to Table 1 is $29.6 \mathrm{MPa}$, tests conducted on dog bone samples with a cross section of $10 \times 5 \mathrm{~mm}$, showed a print tensile strength of $13.25 \mathrm{MPa}$.

The second laps were made of an aluminium flat bar, made of AW-6060 T4 alloy, with the following properties: yield strength $-65 \mathrm{MPa}$, tensile strength $130 \mathrm{MPa}$, elongation at break $13 \%$. The holes in the aluminium laps were made by milling on a CNC machine.

To connect the aluminium and polymer parts, 3 M VHB 5925 double-sided adhesive tape with a thickness of $0.6 \mathrm{~mm}$ and a width of $38 \mathrm{~mm}$ was used. The tape is designed for permanent bonding to irregular surfaces or to powder-skin coated materials and provides good adhesion, with high and medium surface energy to various surfaces, including plastics, paints, metals and glass. One of the mechanisms of adhesion of VHB tape to laps is intermolecular force. This is an electrical interaction that occurs when two molecules are in close proximity to each other. The two surfaces do not stick to each other regardless of how close they are. The reason for this is that the surfaces are rough at the nano level and 
the molecules cannot get close to each other. The VHB tape causes these roughnesses to fill in, resulting in intermolecular forces.

Table 1. Printing parameters and properties of ABS and 3D-printed specimens.

\begin{tabular}{cccc}
\hline Printing Parameters & Values & ABS Parameters & Values \\
\hline Raster angle $\left({ }^{\circ}\right)$ & \pm 45 & Density $\left(\mathrm{g} / \mathrm{cm}^{3}\right)$ & 1.06 \\
\hline Raster width $(\mathrm{mm})$ & 0.4 & Young modulus $(\mathrm{GPa})$ & 2.24 \\
\hline Print tolerance $(\%)$ & \pm 0.2 & Poisson ratio & 0.38 \\
\hline Infill percentage $(\%)$ & 100 & Yield point $(\mathrm{MPa})$ & 20 \\
\hline Layer thickness $(\mathrm{mm})$ & 0.09 & Tensile strength $(\mathrm{MPa})$ & 29.6 \\
\hline Bed temperature $\left({ }^{\circ} \mathrm{C}\right)$ & 80 & Filament diameter $(\mathrm{mm})$ & 1.75 \\
\hline Nozzle diameter $(\mathrm{mm})$ & 0.4 & Diameter tolerance $(\mathrm{mm})$ & \pm 0.05 \\
\hline Printing speed $(\mathrm{mm} / \mathrm{s})$ & 30 & Melting point $\left({ }^{\circ} \mathrm{C}\right)$ & $\sim 250$ \\
\hline Nozzle temperature $\left({ }^{\circ} \mathrm{C}\right)$ & 275 & Thermal conductivity $(\mathrm{W} / \mathrm{mK})$ & 0.16 \\
\hline
\end{tabular}

The manufacturing process of the joints consists of the following steps:

1. A check was done to make sure that all mechanical joints would be able to fit together. If there was significant compression, the geometry had to be corrected.

2. The surface of the aluminium laps was cleaned with Loctite 7061 because coolant and oil were to be used during milling.

3. UNI UV 0.23 primer for VHB tapes was applied to the surfaces of the aluminium and polymer laps.

4. The tape was unrolled and placed on a flat surface with the adhesive side up and then five aluminium laps were placed on it, next to each other, at intervals of a few millimetres.

5. Cutting the tape for each lap was done using a scalpel and a punch of appropriate diameter; holes were made in the tape to match the corresponding holes in the aluminium lap.

6. The protective layer was removed from the tape and bonded to the other polymer lap.

7. The tape was $38 \mathrm{~mm}$ wide and the overlay was $30 \mathrm{~mm}$ wide. The excess tape on the aluminium part was trimmed with a scalpel and then removed from the surface. In this way, the tape's geometry perfectly matched the geometry of the lap.

8. The tape manufacturer requires a low clamping pressure of $100 \mathrm{kPa}$, hence the laps were clamped by hand without any additional tooling. The specimens were tested more than $72 \mathrm{~h}$ after they were made, which, according to the manufacturer, ensures that maximum strength is achieved.

For this type of connection, the strength of the laps exceeded the strength of the connection, hence there was no risk of breakage nor was there any need for bonding the tabs at the ends of the laps. The completed connections (one specimen from each batch) are shown in Figures A1-A3.

Uniaxial tensile tests were performed on an MTS $25 \mathrm{kN}$ testing machine. In order to avoid pre-bending, the specimens due to the geometry of the single-lap model, a sufficient thickness of inserts was used between the grips and the ends of the tabs. The specimens were loaded at a constant displacement increment of $5 \mathrm{~mm} / \mathrm{min}$. Tests were conducted at a temperature of $23^{\circ} \mathrm{C} \pm 2$.

\section{Results and Discussion}

\subsection{Mechanical Response of Reference Specimens " $R$ " Joined by VHB Double-Sided Adhesive Tape}

Although VHB double-sided adhesive tapes are characterised by low maximum stress, high strains to failure result in impressive fracture energy. The failure process often starts with the nucleation of microscopic cracks inside the layer. The failure model is usually 
cohesive, with a layer of tape remaining on both adherends. Operation of the adhesive tape, as shown in Figure 4 for the reference specimens, has several stages. Initially, the force increases linearly; the graph then becomes curved and flattened. This stage continues until about the middle of the strain range, culminating in failure. The final stage is the tape failure process, which initially occurs quite rapidly; however, at about $30 \%$ of the maximum force, the graph begins to smoothly move towards zero. The average maximum force, achieved for the joints made with the VHB tape, was $333 \mathrm{~N}$, which corresponds to a stress of $2.22 \mathrm{MPa}$ in the 3D printed laps. The average energy required to failure, calculated as the area under the force-displacement diagram, was $3 \mathrm{~J}$. These values will be considered as reference and the average values of force and energy for each batch of specimens and work stage will be referred to. The samples after the test are shown in Figure A4. The failure is mainly cohesive in nature. There is also a loss of adhesion between the tape and the aluminum surface and between the tape and the polymer 3D print. The percentages of adhesion failure are $8 \%$ and $17.4 \%$, respectively, considering all samples in the batch.

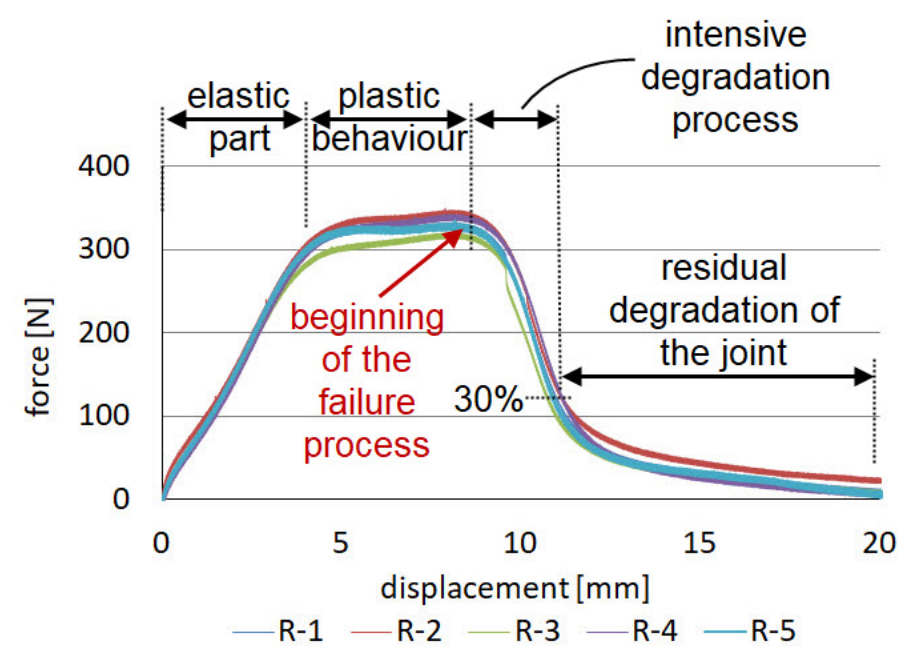

Figure 4. Force-displacement diagrams for reference specimens " $\mathrm{R}$ " joined by VHB double-sided adhesive tape.

\subsection{Mechanical Response of the Single—Lap Joints with One Tenon—Group "A"}

The first type of hybrid joint, labelled "A", was concerned with analysing the effect of the diameter of the mechanical joint. In this case, only one tenon was used, whose diameter varied from $5 \mathrm{~mm}$ to $19 \mathrm{~mm}$. In batches A1 to A4, there was shearing of the mechanical joint and subsequent gradual degradation up to the final failure of the adhesive joint. In the case of specimen A5, the mechanical joint was so strong that the lap breakage occurred at the location of the tenon. By properly selecting the ratio of the area of the tenon and the adhesive tape, not only can different levels of maximum force and energy be obtained, but different characteristics can also be obtained. An analogous phenomenon occurs here, as in [19], where double-sided adhesive tape was also used, while the role of rigid connection was achieved by the point bond of epoxy adhesive. Thus, the " $\mathrm{A}$ " type joints are characterised by a two-stage operation (Figure 5), which is schematically shown in Figure 5f. In the first stage, the rigid mechanical joint works and the load are mainly transferred through the polymeric tenon reaching the $F_{1}$ force. When the tenon is cut by shear loading, the force drops rapidly to $F_{2}$, while the joint does not lose integrity. The load is taken up by the adhesive joint and the force increases, reaching $F_{3}$ again.

The purpose of using polymeric tenons is to increase the strength and stiffness of the joint. For the A1 group of specimens, the maximum force achieved by the mechanical connection is about $26 \%$ lower than the maximum force achieved by reference connection " $R$ ". 
(a)

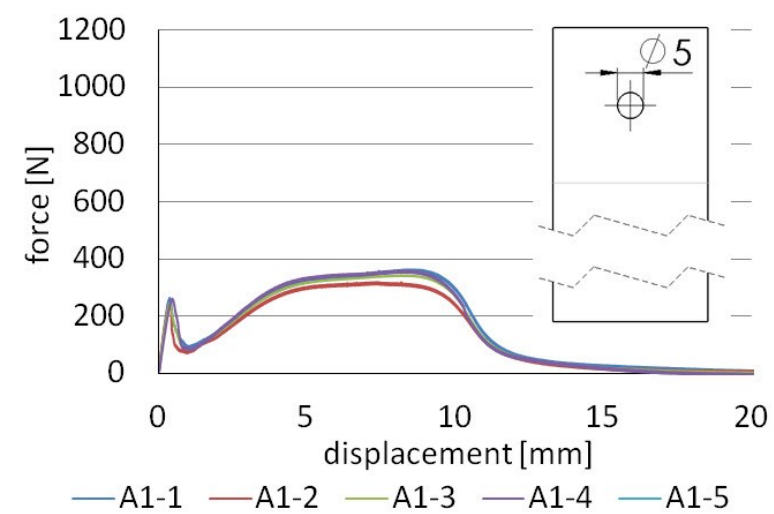

(c)

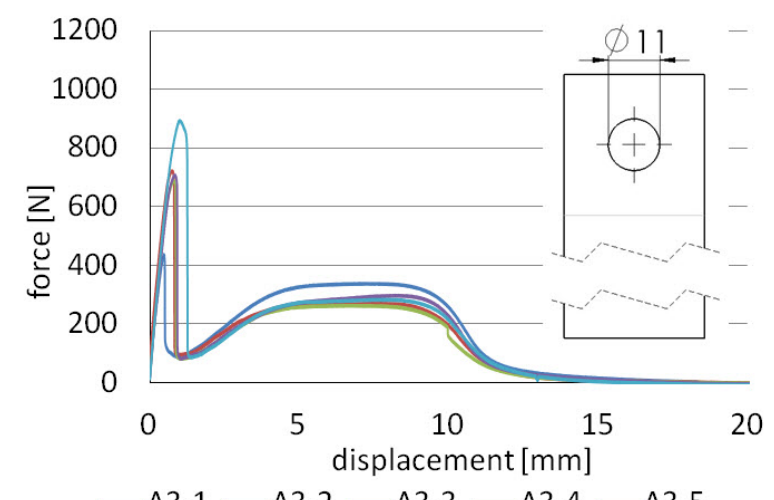

(e)

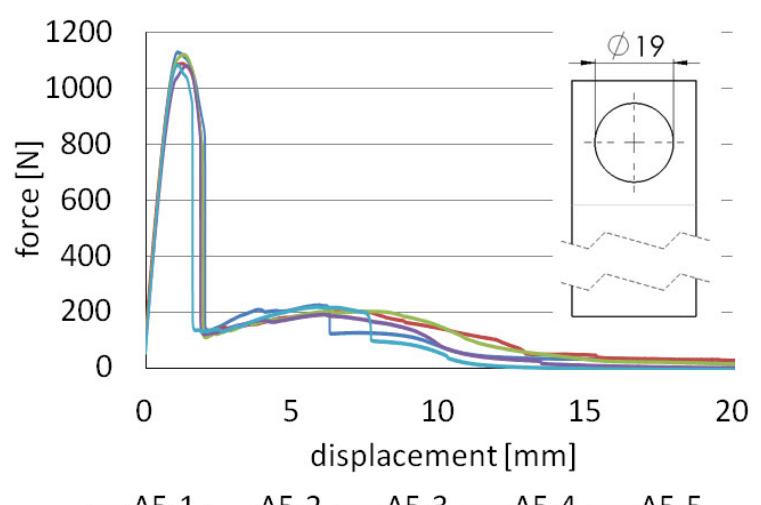

(b)

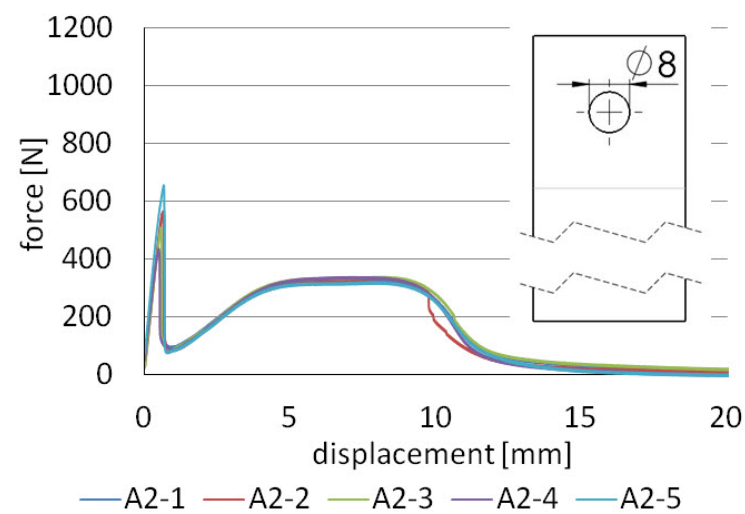

(d)

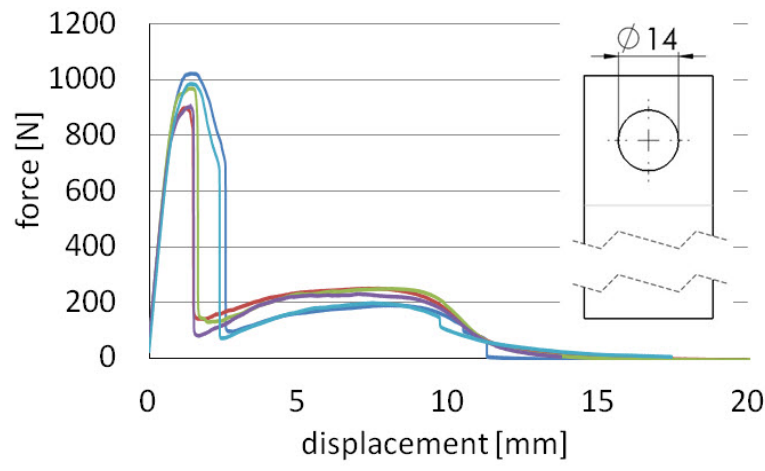

- A4-1 - A4-2 - A4-3-A4-4 - A4-5

(f)

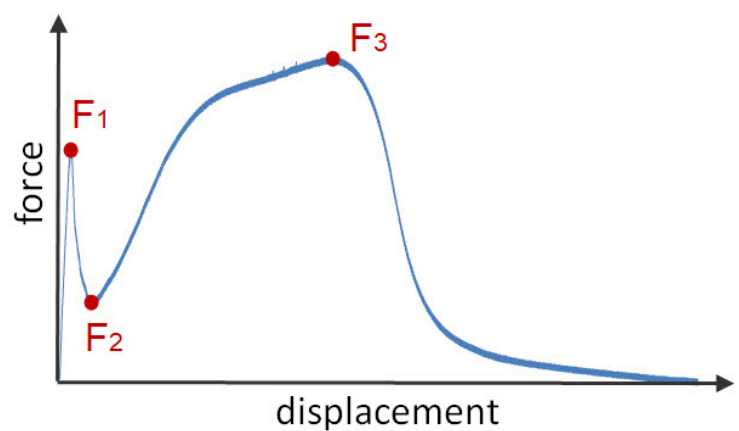

Figure 5. Force-displacement diagrams for models "A": (a) models A1; (b) models A2; (c) models A3; (d) models A4; (e) models A5; (f) working diagram.

When the diameter is increased to $8 \mathrm{~mm}$, the mechanical joint achieves a higher strength, by $46.5 \%$, compared to the reference connection. For A3 series specimens, having a tenon diameter of $11 \mathrm{~mm}$, the mechanical joint achieves about $123 \%$ of the maximum strength of the reference connection " $\mathrm{R}$ ".

Although for the subsequent A4 group, this ratio is even more favourable and the connection has a higher strength, it should be noted that the strength decreases quite sharply in the working stage of the adhesive joint. For the A1 and A2 series, the work of the adhesive tape is similar to that of reference joint " $R$ ". There is no noticeable decrease 
in strength, in this case. The reason for this is that the area occupied by the tenon is small $(11 \%)$ relative to the area of the entire lap. For A4 and A5, the adhesive area of the tape decreases by about $17.1 \%$ and $31.5 \%$, respectively.

Table 2 collects the force values $F_{1}-F_{3}$ and the corresponding stress values $\sigma_{1}-\sigma_{3}$ in the $3 \mathrm{D}$ printed lap outside the joint zone, assuming that it is only in tension.

Table 2. Summary of average $F_{1}, F_{2}$, and $F_{3}$ forces and the corresponding stresses $\sigma_{1}, \sigma_{2}$ and $\sigma_{3}$ in the printed lap outside the joint zone as well as energies for Type A specimens.

\begin{tabular}{cccccc}
\hline & Model A1 & Model A2 & Model A3 & Model A4 & Model A5 \\
\hline $\mathrm{F}_{1}[\mathrm{~N}],\left(\sigma_{1}[\mathrm{MPa}]\right)$ & $246(1.64)$ & $488(3.25)$ & $744(4.96)$ & $953(6.35)$ & $1094(7.29)$ \\
\hline $\mathrm{F}_{2}[\mathrm{~N}],\left(\sigma_{2}[\mathrm{MPa}]\right)$ & $83(0.55)$ & $89(0.59)$ & $90(0.6)$ & $123(0.82)$ & $126(0.84)$ \\
\hline $\mathrm{F}_{3}[\mathrm{~N}],\left(\sigma_{3}[\mathrm{MPa}]\right)$ & $342(2.28)$ & $329(2.19)$ & $277(1.85)$ & $219(1.46)$ & $207(1.38)$ \\
\hline energy $[\mathrm{J}]$ & 3.1 & 3.2 & 2.8 & 3.1 & 3.3 \\
\hline
\end{tabular}

Group A2 should be considered as the best model because, in this case, we obtain a significant increase in stiffness in the initial stage of operation, which does not come at the expense of a decrease in the strength of the adhesive joint. Considering the energy which is needed to the point of the failure of the joint, the A2 model is also, in this respect, the best. An increase of about $6.6 \%$ is obtained compared to the reference model. In general, the highest energy was obtained for model A5, but it should be noted that, in this case, there was no shear failure of the mechanical connections, but rather a fracture of the lap at the tenon location. The samples after the test are shown in Figures A5-A9. As in the reference samples, there is mainly cohesive failure in the tape. There is also a loss of adhesion between the tape and the aluminium surface and between the tape and the polymer 3D print. For example, for samples A1 (Figure A5), the percentage of adhesive failure is 16\% and $15 \%$, respectively, considering all samples in the batch.

\subsection{Mechanical Response of the Joints Having Different Numbers of Tenons-Group B}

Type B specimens, for which the force-displacement diagrams are shown in Figure 6, were made and tested to determine the effect of the number of mechanical joints on their mechanical response. In this case, the polymeric tenon was $5 \mathrm{~mm}$ in diameter for each specimen, having two, three and four tenons. Models B1 (Figure 2a) and B2 (Figure 2b) had two tenons. In the first case, the line on which the tenons were placed, coincided with the axis of the specimen and thus the line of load action. In the second case, the line connecting the two pivots was perpendicular to the line of load action and was located at the midpoint of the lap length (Figure 2b). Failure of single-lap joints often starts at the free edge of the joint between two materials, where there is a stress singularity leading to cracks developing exponentially [39]. Hence, mechanical fasteners are most advantageously placed near the end of the lap region [18]. It is also common to introduce an additional pre-stressing force from the mechanical fastener [40].

Table 3 collects the force values $F_{1}-F_{3}$ and the corresponding stress values $\sigma_{1}-\sigma_{3}$ in the $3 \mathrm{D}$ printed lap outside the joint zone, assuming that it is only in tension.

In the tests conducted, similar values of $\mathrm{F}_{1}$ forces were obtained for $\mathrm{B} 1$ and $\mathrm{B} 2$ specimens; however, a higher value of $\mathrm{F}_{3}$ force and energy in relation to $\mathrm{B} 2$ specimens favours placement along the line of force action.

The next batches of samples to be analysed are groups of specimens B3 and B4. These are analogous to series B1 and B2, the only difference being the introduction of an additional third tenon.

In this case, it is more advantageous to place the row of mechanical joints, perpendicularly to the loading direction. This results in an increase of approximately $19.5 \%$ in the $\mathrm{F}_{1}$ force level, compared to specimen $\mathrm{B} 3$. Both $\mathrm{F}_{2}$ and $\mathrm{F}_{3}$ force and energy levels remain the same for both series types. 
(a)

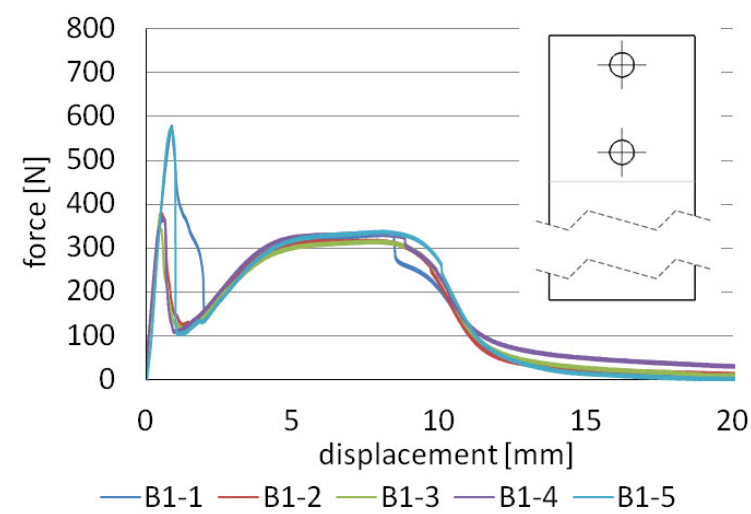

(c)

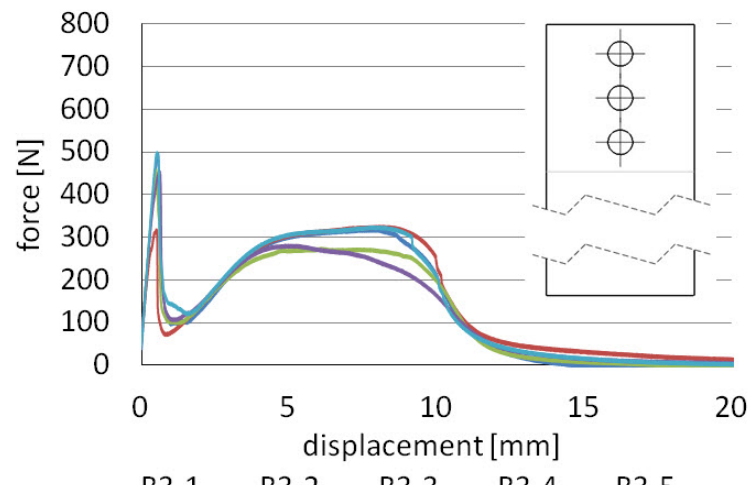

(b)

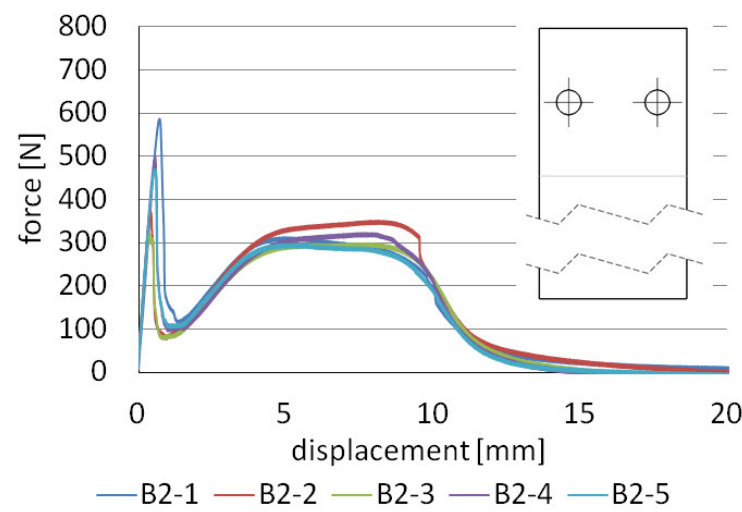

(d)

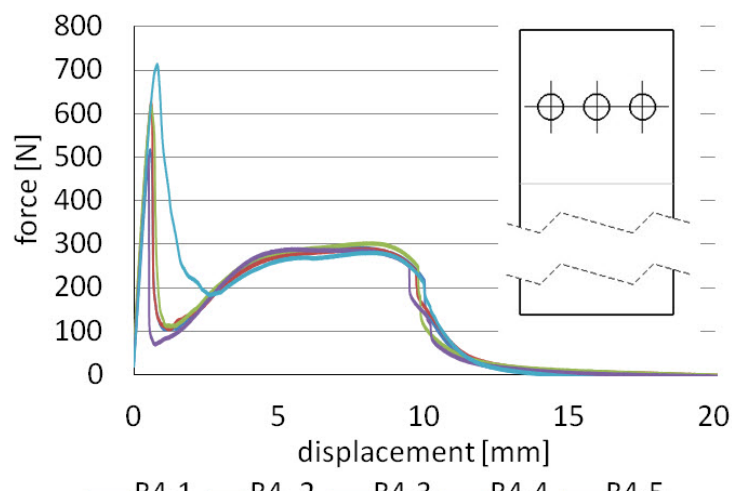

(e)

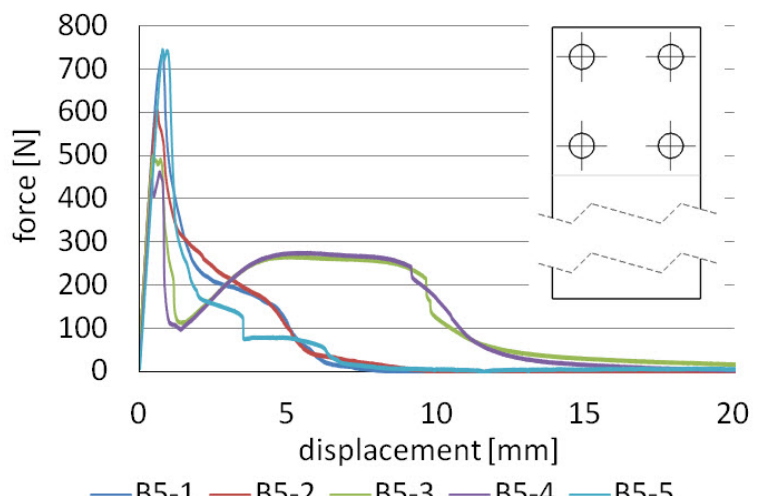

Figure 6. Force-displacement diagrams for "B" models: (a) B1 models; (b) B2 models; (c) B3 models; (d) B4 models; (e) B5 models.

Table 3. Summary of average $F_{1}, F_{2}$, and $F_{3}$ forces and the corresponding stresses $\sigma_{1}, \sigma_{2}$, and $\sigma_{3}$ in the printed lap outside the joint zone as well as energies for Type B specimens.

\begin{tabular}{cccccc}
\hline & Model B1 & Model B2 & Model B3 & Model B4 & Model B5 \\
\hline $\mathrm{F}_{1}[\mathrm{~N}],\left(\sigma_{1}[\mathrm{MPa}]\right)$ & $380(2.53)$ & $395(2.63)$ & $451(3.01)$ & $539(3.59)$ & $591(3.94)$ \\
\hline $\mathrm{F}_{2}[\mathrm{~N}],\left(\sigma_{2}[\mathrm{MPa}]\right)$ & $147(0.98)$ & $101(0.67)$ & $137(0.91)$ & $144(0.96)$ & $104(0.69)$ \\
\hline $\mathrm{F}_{3}[\mathrm{~N}],\left(\sigma_{3}[\mathrm{MPa}]\right)$ & $325(2.16)$ & $305(2.03)$ & $287(1.91)$ & $288(1.92)$ & $270(1.8)$ \\
\hline energy $[\mathrm{J}]$ & 3.3 & 2.8 & 2.8 & 2.7 & 2.8 \\
\hline
\end{tabular}


A different model is that of the B5 group of specimens in which one additional mechanical joint was introduced. These were also repositioned so that they were located at the corners of the overlap. There is an increase in $\mathrm{F}_{1}$ force of about $77 \%$ over the reference model. Although specimen B5 had the smallest adhesive tape area, the energy required to failure is at a level similar to that for models B2, B3 and B4. To the disadvantage of model B5 is the fact that three specimens in this series failed in an unusual way, consisting in the absence of the working stage of the double-sided adhesive tape. Once the maximum $\mathrm{F}_{1}$ force is reached, there is a decrease in its value with varying speed. Initially, the decrease is rapid - to about half of the $F_{1}$ value- but then the graphs become smoother. From this, it can be concluded that the greater the number of mechanical joints, the greater the influence of defects, both in the making of the holes in the tape and in the influence of clearances in the mechanical joints. In order to prevent clearances between tenon and mortise, the authors in [15] proposed an original method by heating a metal lap and forming the heated tenon under pressure. This type of technology can eliminate the clearance; however, its application, in many cases, may be limited because the heating process itself takes a certain amount of time and must be strictly controlled. In order to obtain proper pressure and the plasticisation of the tenon in the groove, the joint must be supported on the other side. Manufacturing this type of specimen and applying it in engineering may be difficult to achieve, especially due to lack of available space.

In conclusion, the most advantageous solution from the group of $B$ models is model $B 1$. In this case, both an increase in the value of $F_{1}$ force by about $14 \%$ in comparison with the reference model " $R$ " and an increase in the energy required to failure of the joint by $10 \%$, are obtained. In addition, the joint shows significant stiffness at the stage of reaching the $F_{1}$ value, while operation of the double-sided adhesive tape provides high safety, since its degradation consumes the most energy. The samples after the test are shown in Figures A10-A14. The cohesive nature of the failure that is characteristic of double-sided VHB tape is most disturbed for samples B5 (Figure A14). In this case, the cohesive failure covers about $46 \%$ of the total surface area, the adhesive failure between the tape and the aluminium surface is as high as $41 \%$, and the adhesive failure between the tape and the 3D printed polymer is $13 \%$, considering all the samples in the batch.

\subsection{Mechanical Response of Hybrid Joints Characterised by Multi-Stage Operation-C Group}

The last type of " $\mathrm{C}$ " models is the most original and advanced. The idea of this type of connection is to achieve multi-stage operation and specific characteristics, through the use of mechanical joints that take part in load transfer in a controlled manner. This is realised by an appropriately sized clearance in one of the laps, by making an elongated hole. In this type of model, there can be different solutions:

(a) all mechanical joints have the same diameter and the holes with which they engage are equally elongated (e.g., C1 Figure 3a),

(b) both tenons are seated in holes of the same diameter and tenons engage with elongated holes of the same length (e.g., C2 Figure 3b, C3 Figure 3c),

(c) there are tenons embedded in holes of the same diameter and tenons engaging with elongated holes of different lengths (e.g., C4 Figure 3d, C5 Figure 3e).

Figure 7 shows the force-displacement diagrams obtained from the laboratory tests, while Figure 8 shows the three different characteristics that correspond to them. The samples after the test are shown in Figures A14-A19. For example, for specimen C1 (Figure A15), the cohesive failure covers $71 \%$ of the lap area, the adhesive failure between the tape and the aluminum surface is $19 \%$, and the adhesive failure between the tape and the $3 \mathrm{D}$ printed polymer is $10 \%$, considering all specimens in the series.

For specimen $\mathrm{C} 1$, the scheme of operation is similar to models A and B, whose characteristics are shown in Figure 5f. In specimen C1, there is an elongated hole, and it is only after some time, with the joint beginning to stretch, that the tenon engages with the hole. Therefore, there is a change in stiffness as indicated by the SC (stiffness change) point in Figure 8a. By changing the length of the hole, it is possible to design which displacement 
(load) the joint starts to resist more. Further operation takes place as for models A and B and three levels of forces $\mathrm{F}_{1}, \mathrm{~F}_{2}$, and $\mathrm{F}_{3}$ can be distinguished.

The second group of models are $\mathrm{C} 2$ and $\mathrm{C} 3$. Their operating characteristics are shown in Figure 8b.

(a)

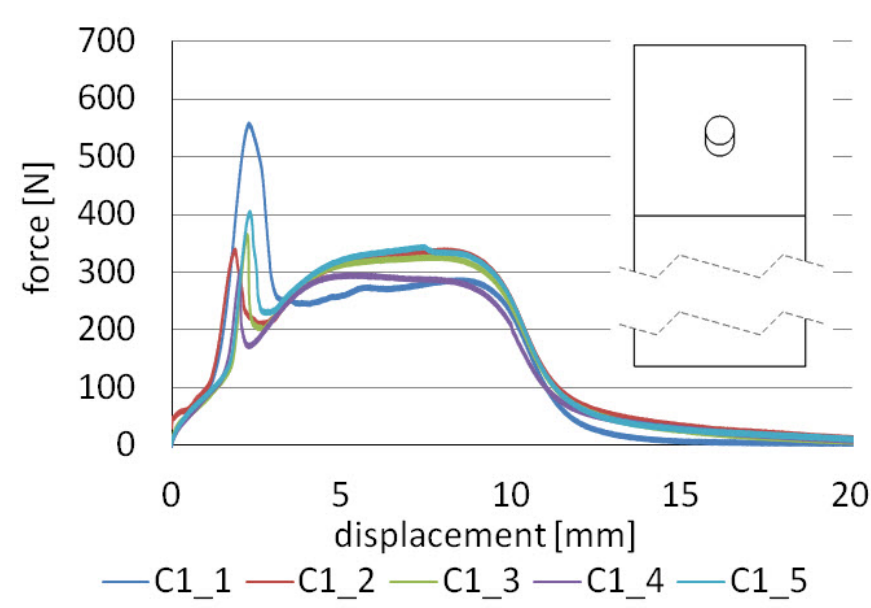

(c)

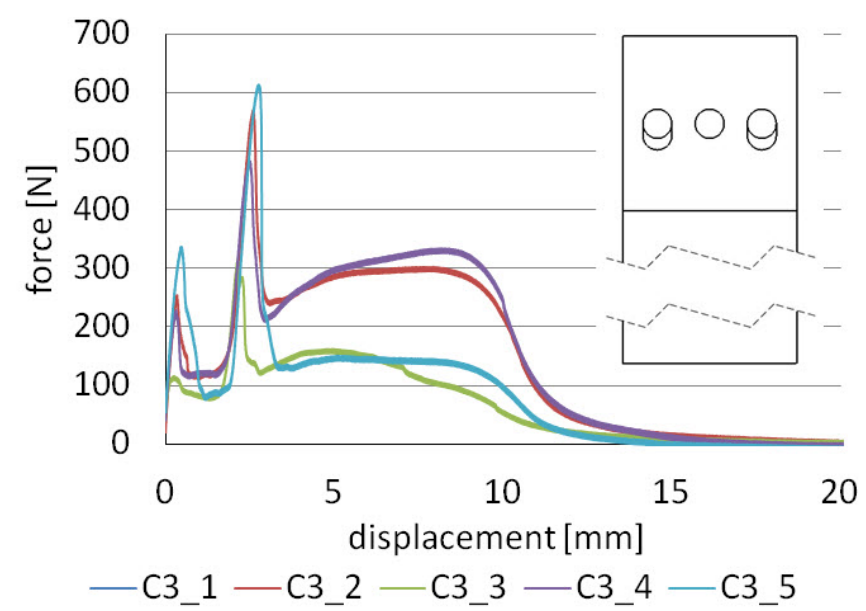

(b)

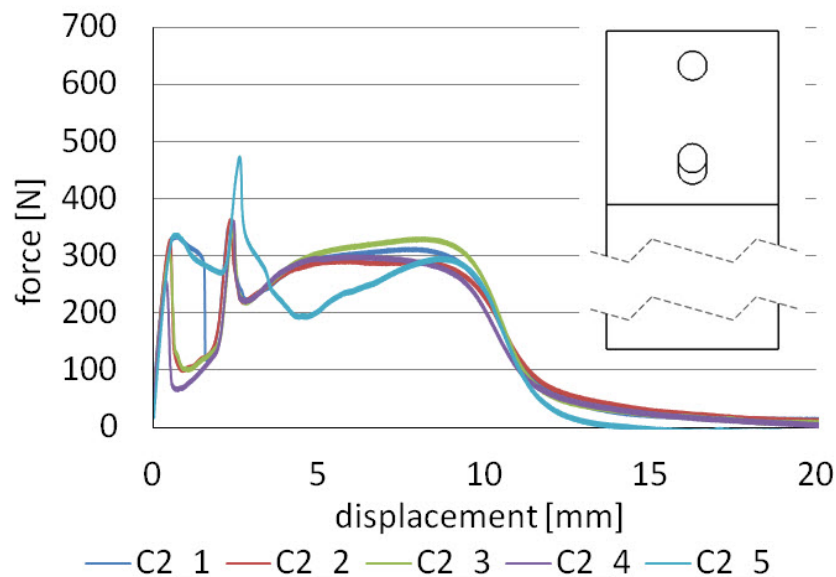

(d)

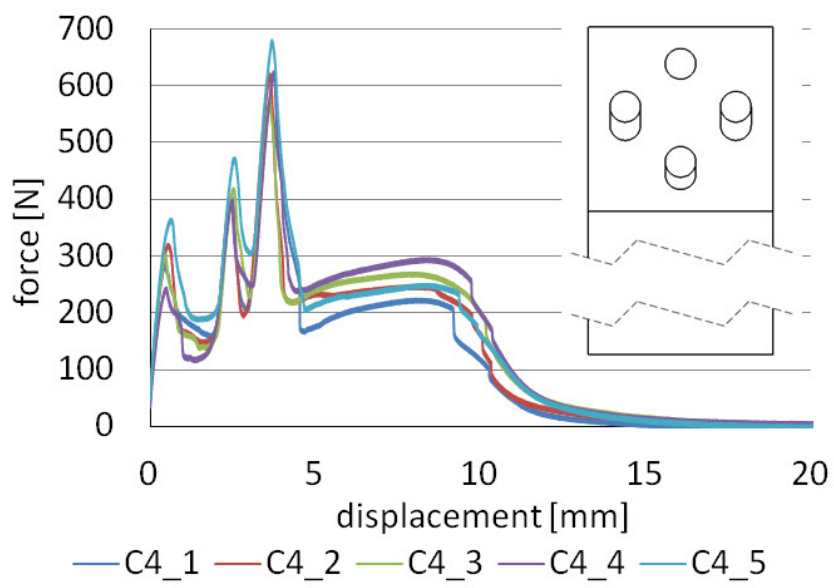

(e)

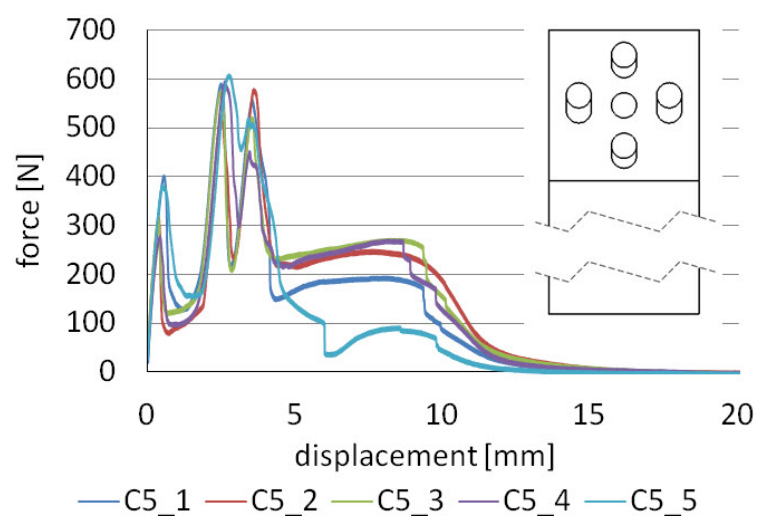

Figure 7. Force-displacement diagrams for “C" models: (a) C1 models (Figure 3a); (b) C2 models (Figure 3b); (c) C3 models (Figure 3c); (d) C4 models (Figure 3d); (e) C5 models (Figure 3e). 
Already, from the beginning of the load, with these models, one of the tenons engages with the hole. The joint therefore has a much higher stiffness than if only the double-sided adhesive tape was working i.e., model " $R$ ". In the next stage, when force $F_{1}$ is reached, the tenon is cut due to shear and the force drops to $F_{2}$, the load being carried by the adhesive tape. In the third stage, other mechanical joints engage with the holes and the force increases again to $F_{3}$. The fourth and final stage occurs after all tenons have been sheared and the load is again taken up by the adhesive tape. Of course, force levels $F_{1}$ and $\mathrm{F}_{2}$ can differ, depending on the diameter value and the number of tenons for each stage.

(a)

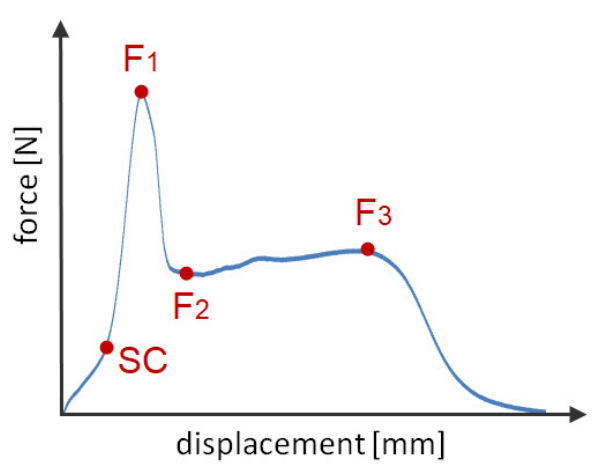

(b)

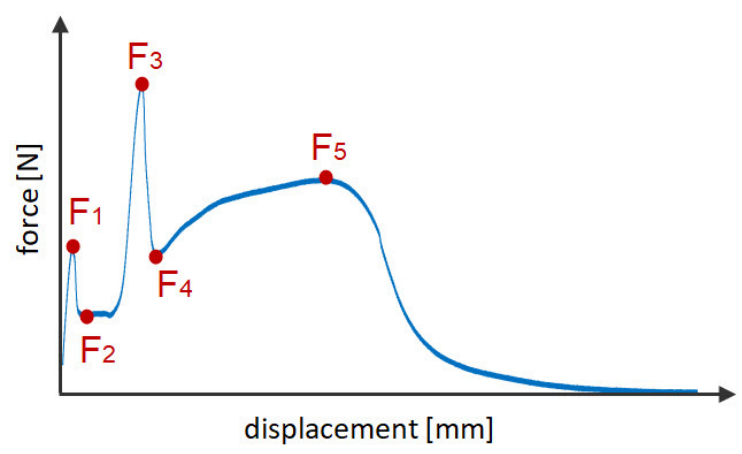

(c)

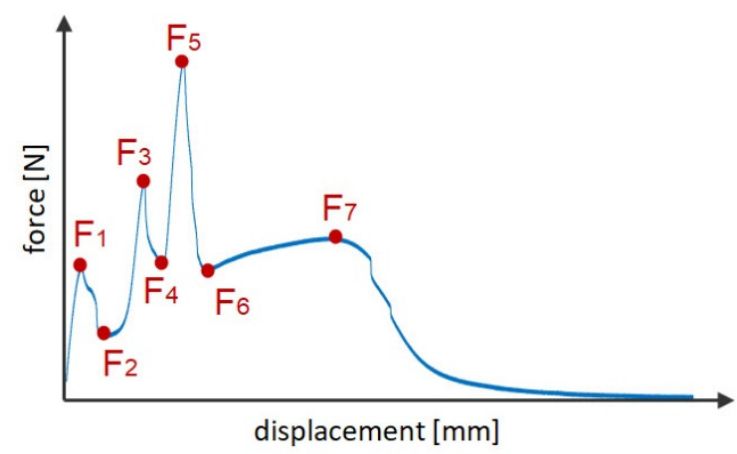

Figure 8. Schematics of connections: (a) C1; (b) C2; C3; (c) C4; C5.

The last group of joints C4 and C5 (Figure 8c) is the most advanced because there are as many as six stages of operation - three stages of mechanical joint operation and three stages of adhesive tape operation. To achieve this effect, one of the laps must have both holes with diameters corresponding to the mating tenons and two types of enlarged holes. By properly selecting the diameters of the tenons and the length of the enlarged holes, it is possible to obtain different force ratios $F_{1}, F_{3}, F_{5}$ and $F_{7}$. The disadvantage of this type of solution is that more effort is required to drill the holes and high precision must be exercised.

Table 4 collects the force values $F_{1}-F_{7}$ and the corresponding stress values $\sigma_{1}-\sigma_{7}$ in the $3 \mathrm{D}$ printed lap outside the joint zone, assuming that it is only in tension. Analysis and discussion of the results for the $C$ series will begin with a comparison of the A1 and $\mathrm{C} 1$ models. Both types of connections have one tenon with the same diameter of $5 \mathrm{~mm}$. According to Tables 2 and 4, the $\mathrm{F}_{1}$ forces are $246 \mathrm{~N}$ and $340 \mathrm{~N}$, respectively. Thus, the application of additional clearance in the hole allows an increase in the $F_{1}$ force of about $38 \%$. This large increase can be explained by the fact that, in the case of model A1, the double-sided adhesive tape is completely relieved when it is loaded. In the case of model C1, there is already considerable deformation in the tape and the mechanical fastener 
engages smoothly with the whole joint. However, there is a question as to what the value of the $F_{1}$ force would be if the mechanical fastener were to come into contact with the hole, at the stage where the double-sided adhesive tape reached its maximum force value, i.e., in the displacement range of about 4-9 $\mathrm{mm}$. This type of model will be the subject of on-going laboratory tests. Note, however, that, for model C1, there is a change in stiffness (point SC of Figure 8a).

Table 4. Summary of average $F_{1}-F_{7}$ forces and the corresponding stresses $\sigma_{1}-\sigma_{7}$ in the printed lap outside the joint zone as well as energies for Type $C$ specimens.

\begin{tabular}{cccccc}
\hline & Model C1 & Model C2 & Model C3 & Model C4 & Model C5 \\
\hline$F_{1}[\mathrm{~N}],\left(\sigma_{1}[\mathrm{MPa}]\right)$ & $340(2.32)$ & $285(1.90)$ & $219(1.46)$ & $291(1.94)$ & $310(2.07)$ \\
\hline $\mathrm{F}_{2}[\mathrm{~N}],\left(\sigma_{2}[\mathrm{MPa}]\right)$ & $233(1.55)$ & $151(1.01)$ & $98(0.65)$ & $156(1.04)$ & $124(0.83)$ \\
\hline $\mathrm{F}_{3}[\mathrm{~N}],\left(\sigma_{3}[\mathrm{MPa}]\right)$ & - & $347(2.31)$ & $420(2.8)$ & $411(0.27)$ & $552(3.68)$ \\
\hline $\mathrm{F}_{4}[\mathrm{~N}],\left(\sigma_{4}[\mathrm{MPa}]\right)$ & - & $241(1.61)$ & $184(1.23)$ & $246(1.64)$ & $329(2.19)$ \\
\hline $\mathrm{F}_{5}[\mathrm{~N}],\left(\sigma_{5}[\mathrm{MPa}]\right)$ & - & - & - & $598(3.99)$ & $514(3.43)$ \\
\hline $\mathrm{F}_{6}[\mathrm{~N}],\left(\sigma_{6}[\mathrm{MPa}]\right)$ & - & - & $221(1.47)$ & $197(1.31)$ \\
\hline $\mathrm{F}_{7}[\mathrm{~N}],\left(\sigma_{7}[\mathrm{MPa}]\right)$ & $313(2.09)$ & $300(2.00)$ & 3 & $251(1.67)$ & 2.8 \\
\hline energy $[\mathrm{J}]$ & 3 & $31.51)$ & & 2.5 \\
\hline
\end{tabular}

In the four-stage $\mathrm{C} 3$ model, the predicted effect of giving a larger $\mathrm{F}_{3}$ force was obtained compared to the $\mathrm{C} 2$ model. This effect was achieved by having two tenons come into contact with a delay rather than one, as is the case in model C2. The percentage difference in this case is approximately $21 \%$.

The common feature of C4 and C5 models is that, in the initial stage, one tenon is working; therefore, $\mathrm{F}_{1}$ forces are at a similar level. The second and third stages of the mechanical connections are already different, due to the different number of tenons, coming in contact with the holes; hence, forces $\mathrm{F}_{3}$ and $\mathrm{F}_{5}$ are different. For the $\mathrm{C} 5$ models, the lowest value of force $F_{7}$ is also obtained and is $36 \%$ lower compared to the reference model " $R$ ". The explanation for this decrease is related to the making of as many as five holes in the adhesive tape, which results in a weakening of the tape. The use of one or two tenons in the lap does not reduce the energy required for them to fail. For models C1 and C2, the same values were obtained as for the reference model " $R$ ". However, the energy reduction is very negatively affected by placing three tenons in one row, perpendicular to the direction of the load action. In this case, the decrease of this parameter is as much as $23 \%$. Similarly, for model B4, the lowest energy value in the entire " $\mathrm{B}$ " series was also obtained.

\subsection{Scatter Analysis of the Results}

Figure 9 shows the relative standard deviation for all series for maximum force. The " $R$ " reference samples achieved a value of $13.3 \%$. This is not a large value considering that operations such as cutting the double-sided tape and joining the laps were performed manually, without the use of special positioning devices. Therefore, one cannot have any objections to the " $\mathrm{A}$ " series. In this case, the maximum value was obtained for model A2 and was $13.2 \%$. Samples A5 have a very low \% RSD parameter because, in this case, there was a breakage of the polymer laps. The " $\mathrm{B}$ " group is dominated by values of $20 \%$; only samples B3 obtained a \% RSD level of almost 33\%. The increase in value of this parameter is associated with a higher degree in the complexity of the geometry, making more holes, which must be fitted properly. Interesting results were obtained for the " $\mathrm{C}$ " group; on the one hand, there is a very low repeatability of results in relation to the maximum force for C3 samples ( $45 \%$ RSD). On the other hand, there is also a very low value of $2 \%$ for specimen C5, which can be explained by the fact that the fasteners are uniformly distributed in the lap and come into contact with the holes in a smooth manner. 
The nature of the joint failure using VHB tape may also influence the scatter in results. Theoretically, only cohesive failure should occur in the tape volume, but, regardless of the type of specimen, there is additionally adhesive failure between the tape and the surface of the aluminium adherend and between the tape and the surface of the 3D printed polymer. The largest share of cohesive failure (about 74.6\%) occurs in the reference samples. After the insertion of tenons in the B and C series samples, the percentage of cohesive failure decreases. The reason may be the fragments of tenons after their failure, which, moving together with the lap, cause tearing of the tape and change the nature of its failure to adhesive.

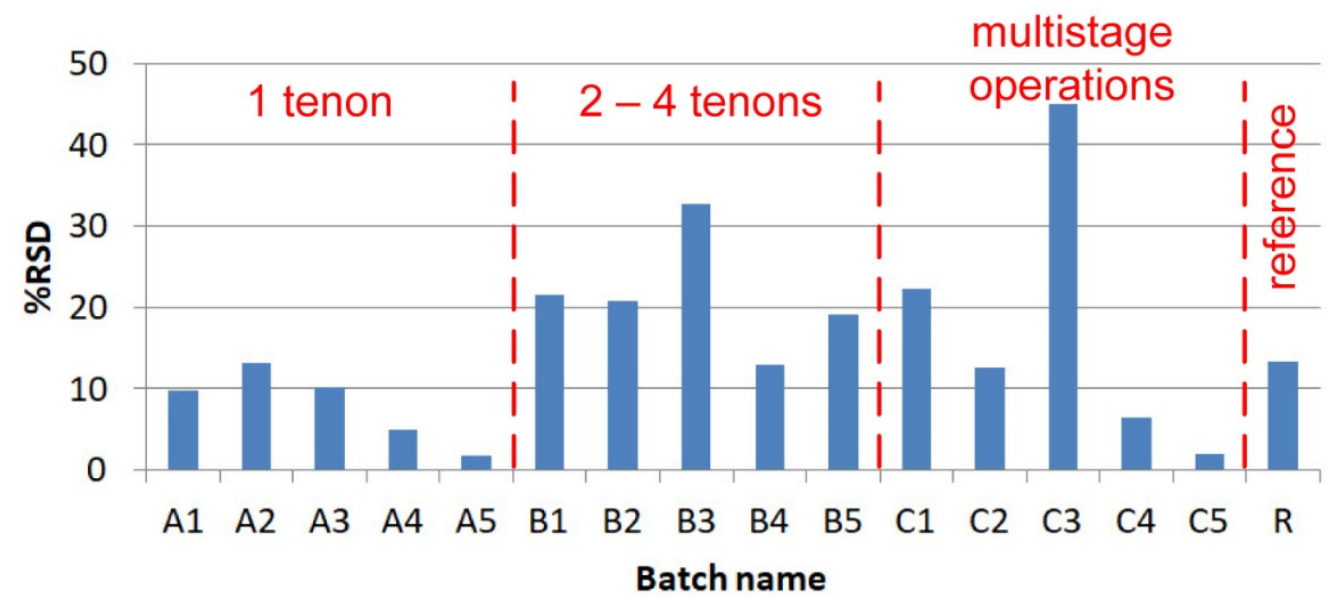

Figure 9. Relative standard deviation.

The results of the laboratory tests obtained can be a valuable source of data for calibrating numerical models, which is necessary because, as shown in the current paper, the number of combinations of the use of mechanical joints can be very large.

\section{Conclusions}

This paper presents three groups of original and innovative single-lap joints that are made using double-sided adhesive tape and mechanical joints by tenons. The manner in which their manufacture is implemented is described in detail. The study of lap joints was carried out on a total of 80 samples in which one of the laps was 3D printed, Z-ABS material and the other was made of aluminium. Joining of $3 \mathrm{D}$ printouts is a new issue and has been put into practice in many ways. However, no connections as advanced as those presented in this paper have been encountered. As the results of the tests illustrate, the following conclusions can be formulated:

- the introduction of mechanical joints, depending on the number and diameter of tenons, does not cause too high an increase in the energy required to cause the joints to fail, in comparison to the reference model $\mathrm{R}$ (maximum 10\%). More often, there is a decrease of this parameter even by as much as $23 \%$. This is because the polymeric tenon is much stiffer than the VHB tape, but it fails at small strains, hence the total energy is similar in each case,

- the introduction of mechanical connections significantly increases joint stiffness and maximum force. The largest increase was obtained for model A4 and was equal to $186 \%$, compared to the reference model,

- the proportional increase of the tenon area, in the group A specimens, also results in a proportional increase in maximum force, with the operation of these joints being a two-stage process,

- $\quad$ increasing the tenon area, in the group A specimens, decreases the force transferred by the double-sided adhesive tape in the second stage, but all joints, regardless of tenon area, fail at the same displacement,

- the most advantageous solution from group B is model B1 which achieves both an increase in $F_{1}$ force of about $14 \%$ in comparison to reference model $\mathrm{R}$ and above a $10 \%$ increase in the energy required to cause the joint to fail. 
- $\quad$ specimens of the group $C$ have the greatest potential for the arbitrary shaping of the characteristics of lap joints. The four- and six-stage joints, as designed, can significantly increase the safety of the structural elements,

- Four types of failure were observed during the study. The first is the cohesive failure that occurs in the volume of the VHB tape; the effect is that it remains on both surfaces of the laps. The second type consists of deformation and finally shearing of the polymeric tenons. The third type of failure, which occurs in almost every sample, is the loss of adhesion between the VHB tape and the laps. The last type of failure, which occurred in two A4 series specimens and all A5 series specimens, is cracking of the polymer laps at the tenon location.

Author Contributions: Conceptualization, P.G.; Methodology, P.G.; Software, D.P., P.G. and M.N.; Validation, P.G. and T.S.; Formal Analysis, M.N. and T.S.; Investigation, D.P. and M.N.; Resources, T.S. and M.N.; Data Curation, D.P. and P.G.; Writing—Original Draft Preparation, P.G.; Writing—Review and Editing, M.N., P.G. and T.S.; Visualization, D.P. and P.G.; Supervision, T.S.; Project Administration, M.N.; Funding Acquisition, M.N. All authors have read and agreed to the published version of the manuscript.

Funding: The project/research was financed within the framework of the project of the Lublin University of Technology-Regional Excellence Initiative, funded by the Polish Ministry of Science and Higher Education (contract no. 030/RID/2018/19) and Polish Ministry of Science and Higher Education (Poland-contract FN 20/ILT/2021).

Institutional Review Board Statement: Not applicable.

Informed Consent Statement: Not applicable.

Data Availability Statement: The data presented in this study are available on request from the corresponding author.

Conflicts of Interest: The authors declare no conflict of interest.

\section{Appendix A}

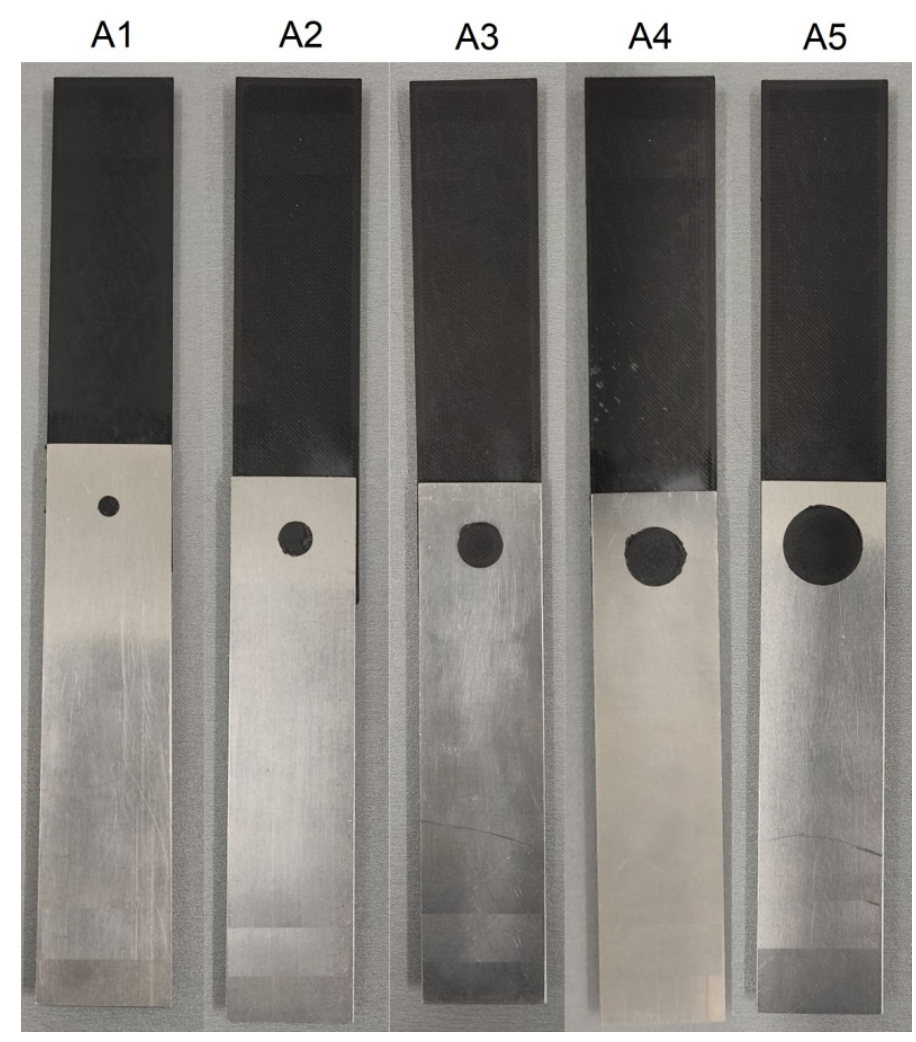

Figure A1. Samples A before the test. 


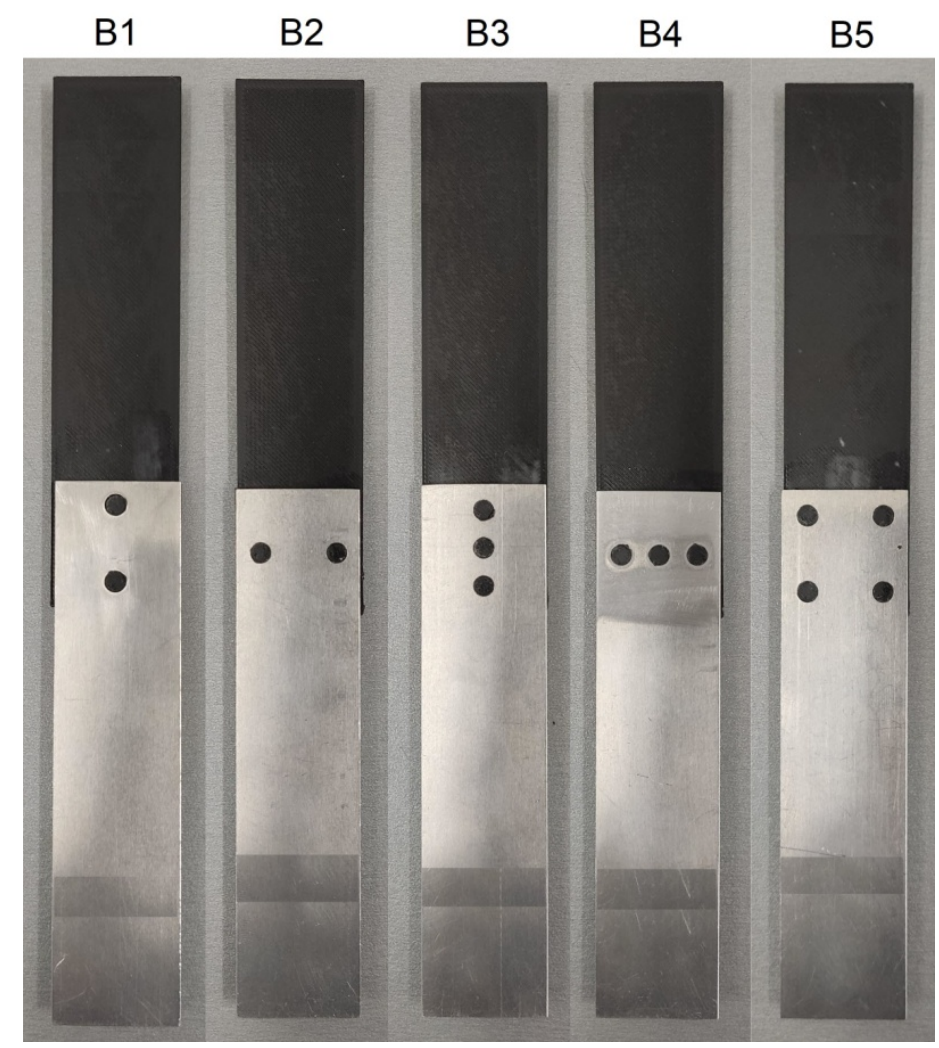

Figure A2. Samples B before the test.

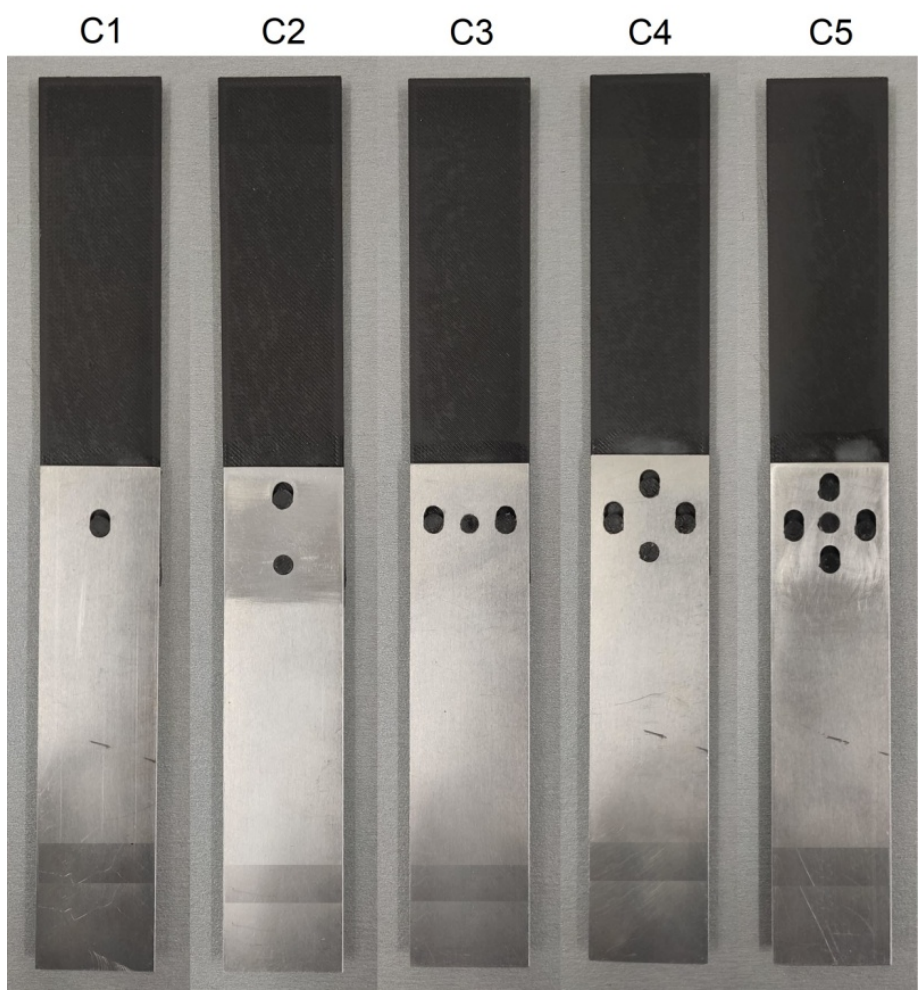

Figure A3. Samples $C$ before the test. 


\section{Appendix B}

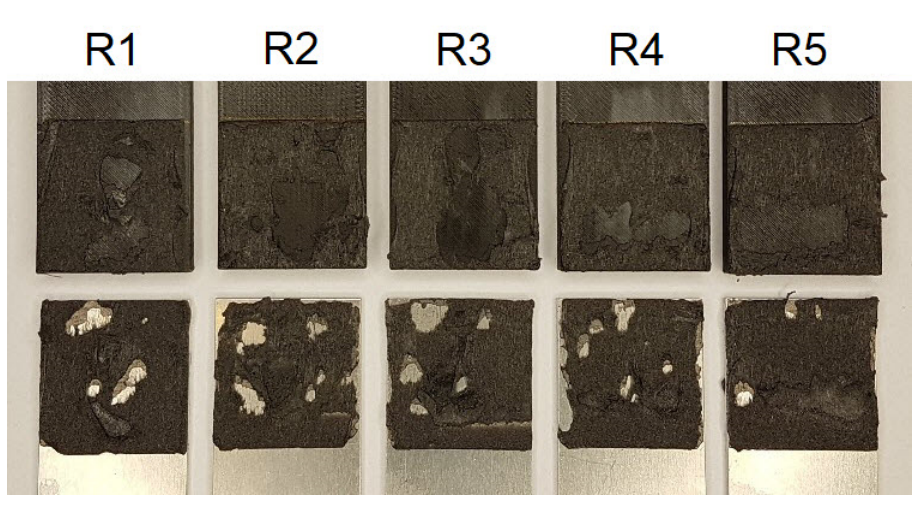

Figure A4. Reference samples after the tensile test.

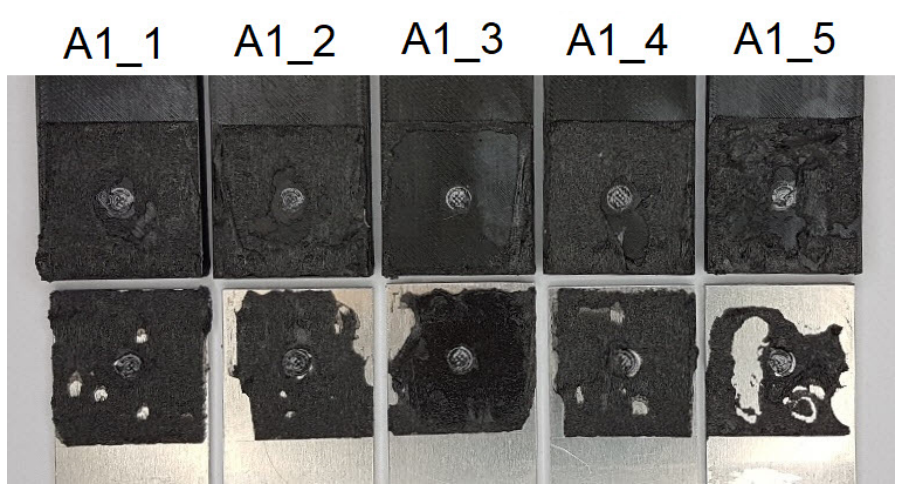

Figure A5. Samples A1 after the tensile test.

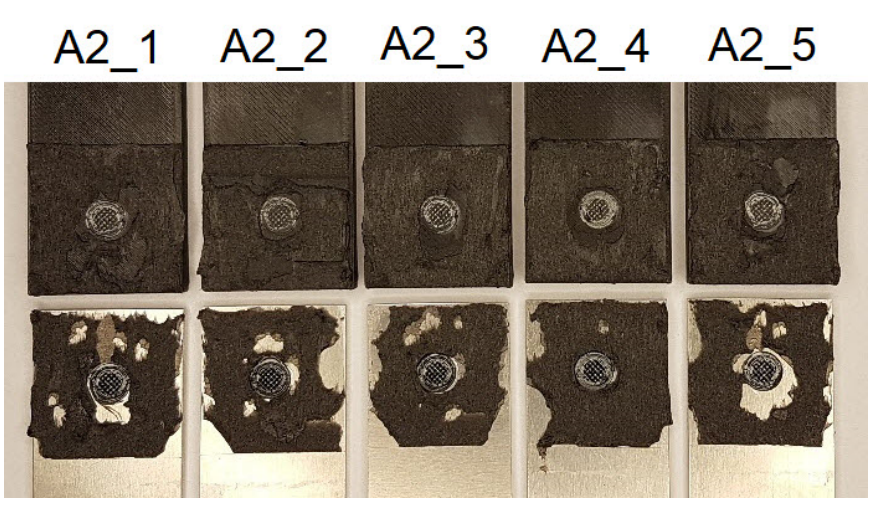

Figure A6. Samples A2 after the tensile test.

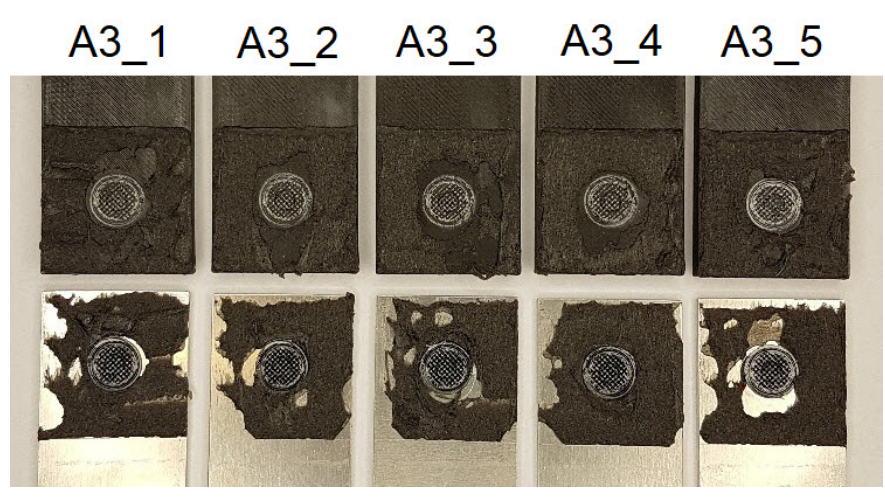

Figure A7. Samples A3 after the tensile test. 


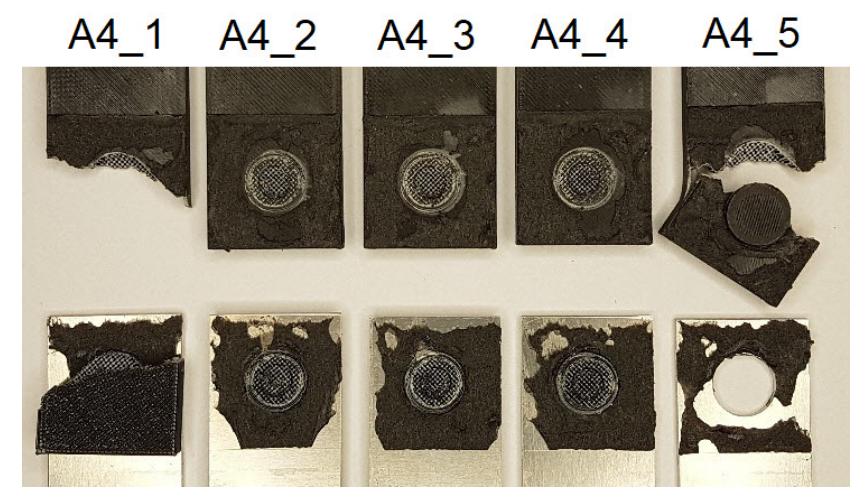

Figure A8. Samples A4 after the tensile test.

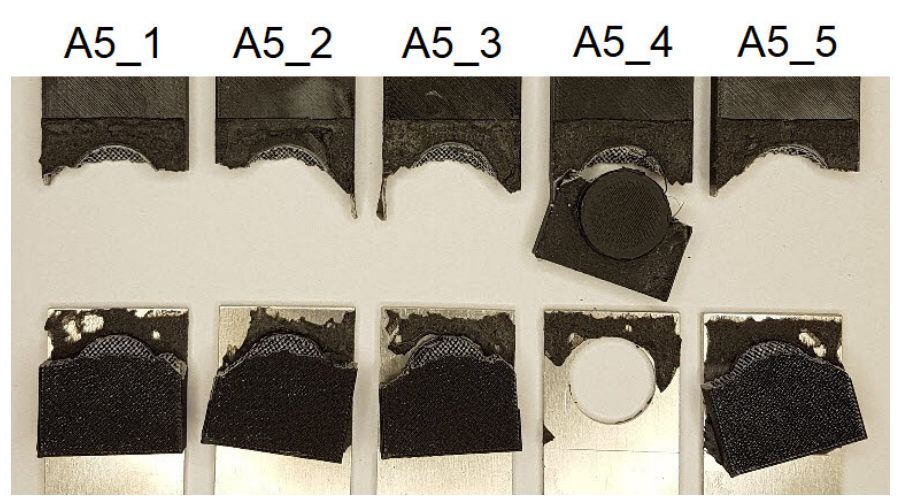

Figure A9. Samples A5 after the tensile test.

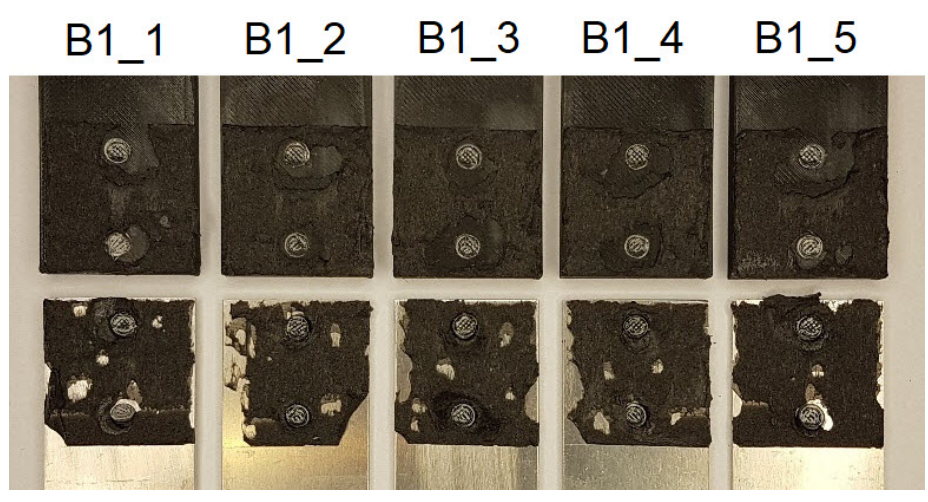

Figure A10. Samples B1 after the tensile test.

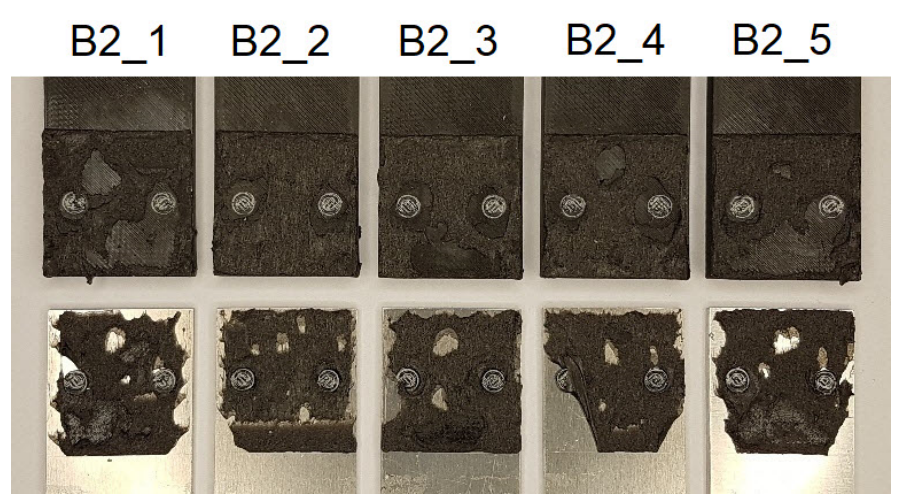

Figure A11. Samples B2 after the tensile test. 


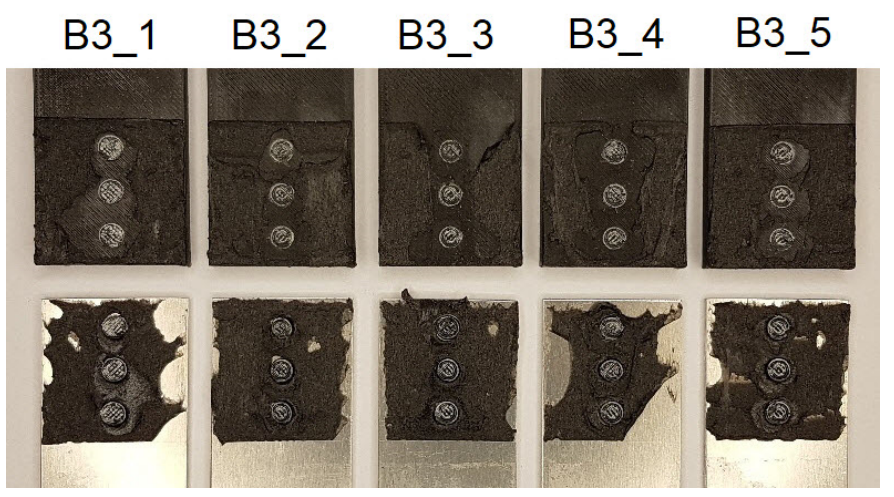

Figure A12. Samples B3 after the tensile test.

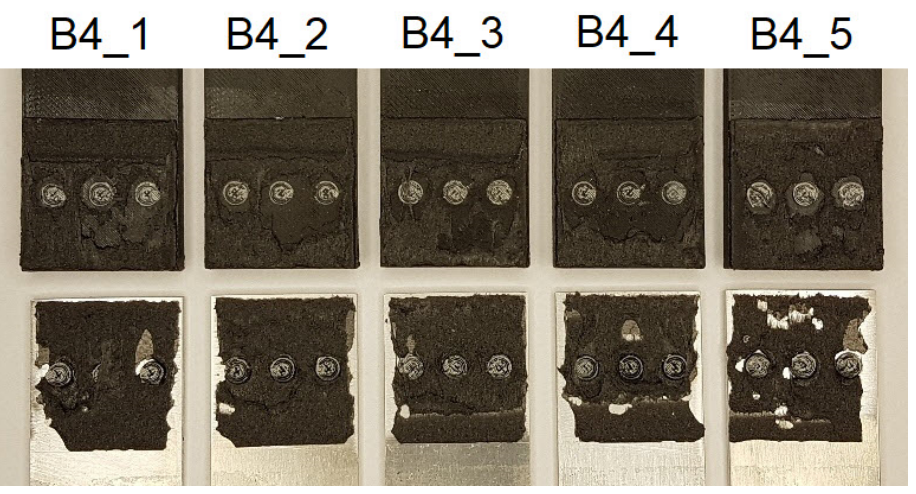

Figure A13. Samples B4 after the tensile test.

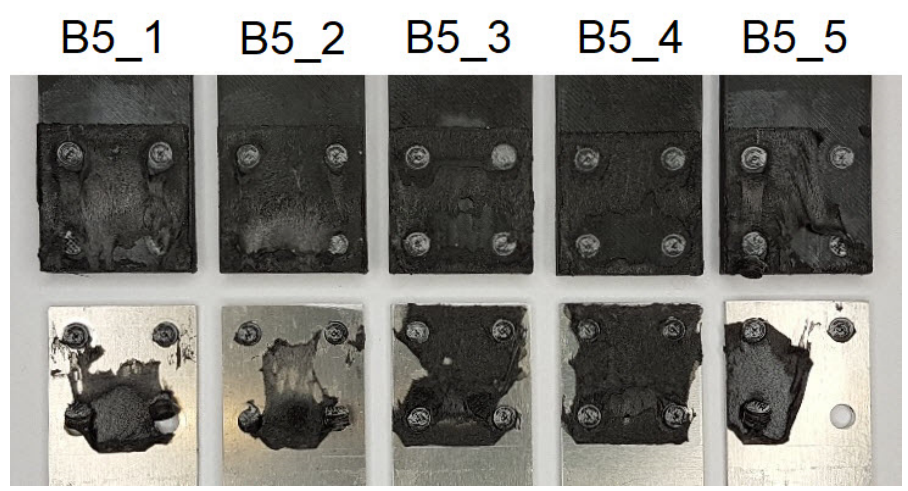

Figure A14. Samples B5 after the tensile test.

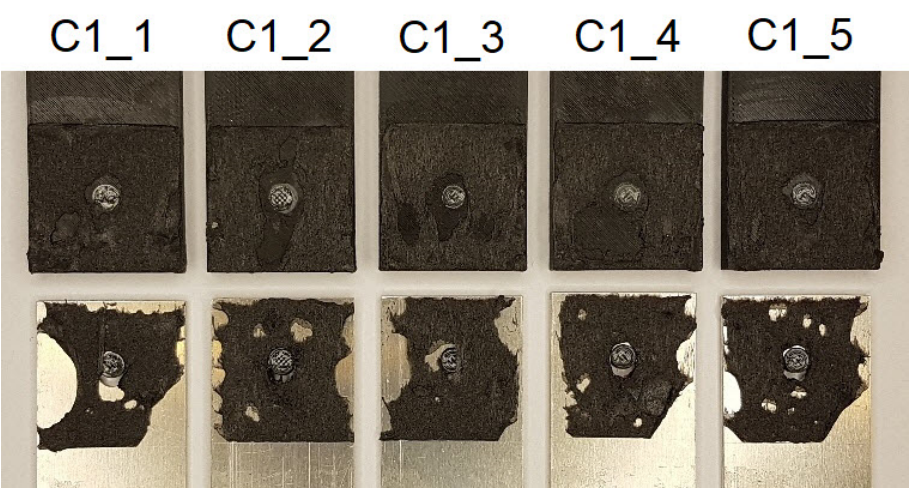

Figure A15. Samples C1 after the tensile test. 


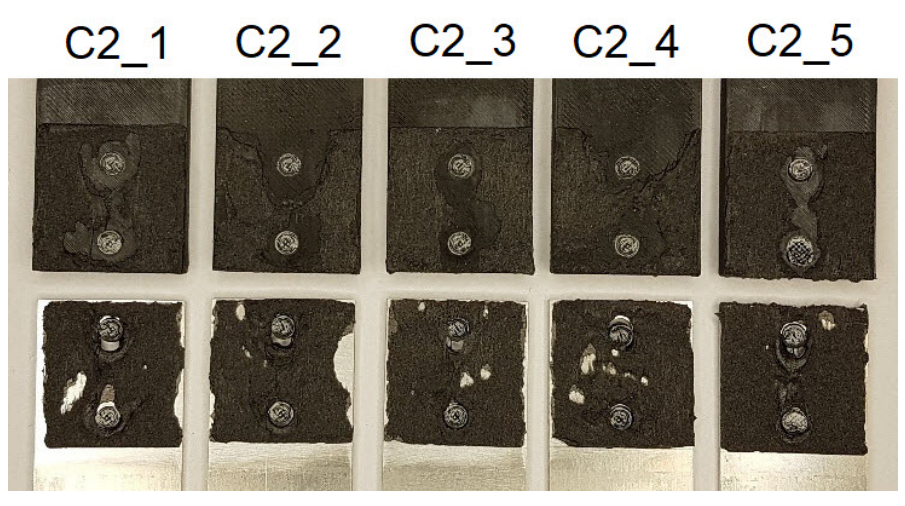

Figure A16. Samples C2 after the tensile test.

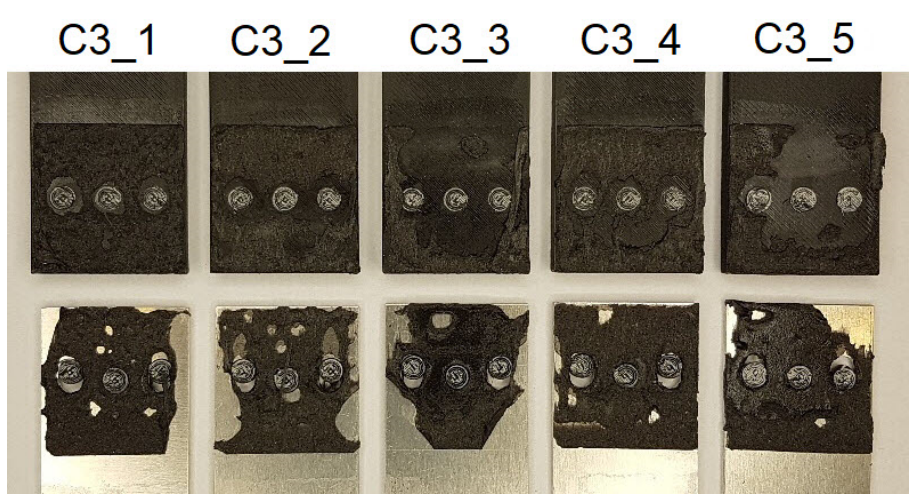

Figure A17. Samples C3 after the tensile test.

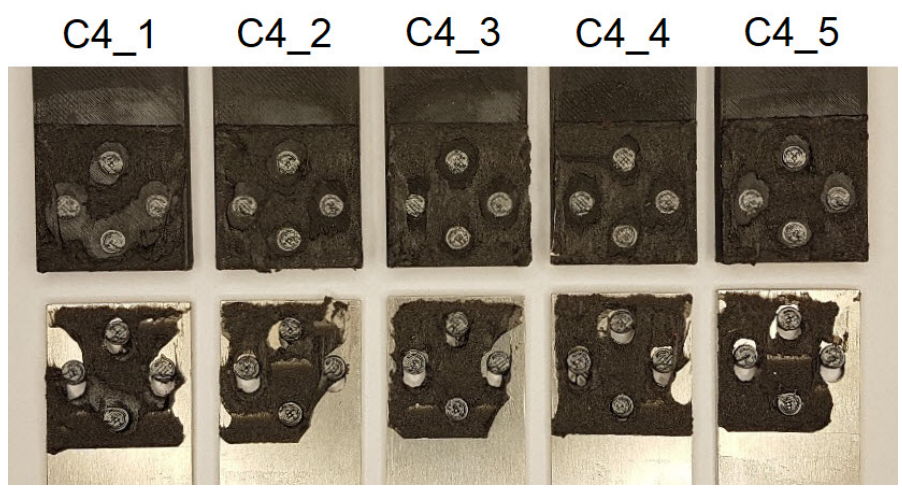

Figure A18. Samples C4 after the tensile test.

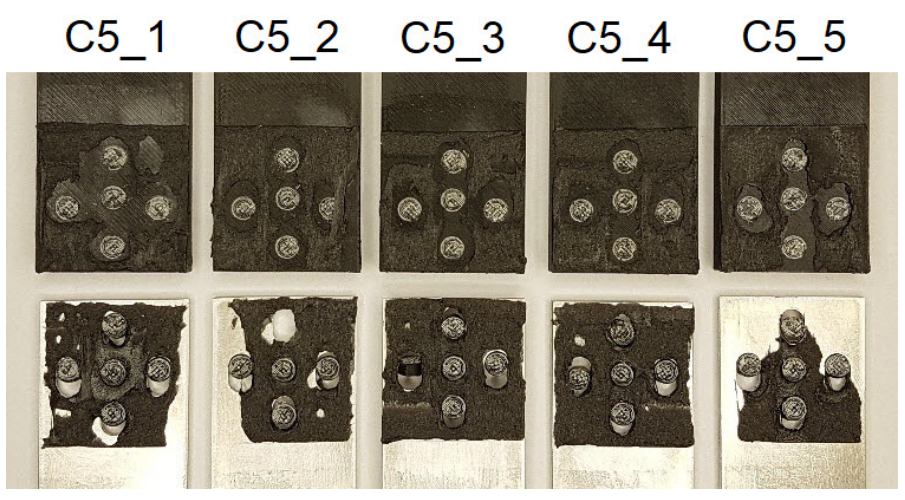

Figure A19. Samples C5 after the tensile test. 


\section{References}

1. Garcia, R.; Prabhakar, P. Bond interface design for single lap joints using polymeric additive manufacturing. Compos. Struct. 2017, 176, 547-555. [CrossRef]

2. Dahmen, V.; Redmann, A.J.; Austermann, J.; Quintanilla, A.L.; Mecham, S.J.; Osswald, T.A. Fabrication of hybrid composite T-joints by co-curing with 3D printed dual cure epoxy. Compos. Part B Eng. 2020, 183, 107728. [CrossRef]

3. Albahri, R.; Yoon, H.-I.; Lee, J.D.; Yoon, S.-N.; Lee, S.J. Shear bond strength of provisional repair materials bonded to 3D printed resin. J. Dent. Sci. 2021, 16, 261-267. [CrossRef]

4. Sadowski, T.; Golewski, P. Effect of Tolerance in the Fitting of Rivets in the Holes of Double Lap Joints Subjected to Uniaxial Tension. Key Eng. Mater. 2014, 607, 49-54. [CrossRef]

5. Sadowski, T.; Kneć, M.; Golewski, P. Fatigue Response of the Hybrid Joints Obtained by Hot Spot Welding and Bonding Techniques. Key Eng. Mater. 2014, 601, 25-28. [CrossRef]

6. Więckowski, W.; Lacki, P.; Adamus, J. Examinations of steel overlap joints obtained using the friction stir welding technology. Arch. Metall. Mater. 2019, 64, 393-399. [CrossRef]

7. Wang, W.; Wang, S.; Zhang, X.; Xu, Y.; Tian, Y.; Huang, H. Enhanced aluminum alloy-polymer friction stir welding joints by introducing micro-textures. Mater. Lett. 2021, 295, 129872. [CrossRef]

8. Wang, T.; Upadhyay, P.; Rabby, R.-E.; Li, X.; Li, L.; Soulami, A.; Kappagantula, K.S.; Whalen, S. Joining of thermoset carbon fiber reinforced polymer and AZ31 magnesium alloy sheet via friction stir interlocking. Int. J. Adv. Manuf. Technol. 2020, 109, 689-698. [CrossRef]

9. Balawender, T. The Ability to Clinching as a Function of Material Hardening Behavior. Acta Met. Slovaca 2018, $24,58-64$. [CrossRef]

10. Abibe, A.B.; Amancio-Filho, S.T.; dos Santos, J.; Hage, E. Mechanical and failure behaviour of hybrid polymer-metal staked joints. Mater. Des. 2013, 46, 338-347. [CrossRef]

11. Baptista, R.; Pragana, J.; Bragança, I.; Silva, C.; Alves, L.; Martins, P. Joining aluminium profiles to composite sheets by additive manufacturing and forming. J. Mater. Process. Technol. 2020, 279, 116587. [CrossRef]

12. Bergmann, J.P.; Stambke, M. Potential of Laser-manufactured Polymer-metal hybrid Joints. Phys. Procedia 2012, 39, 84-91. [CrossRef]

13. Schricker, K.; Stambke, M.; Bergmann, J.P.; Bräutigam, K.; Henckell, P. Macroscopic Surface Structures for Polymer-metal Hybrid Joints Manufactured by Laser Based Thermal Joining. Phys. Procedia 2014, 56, 782-790. [CrossRef]

14. Konchakova, N.; Balle, F.; Barth, F.; Mueller, R.; Eifler, D.; Steinmann, P. Finite element analysis of an inelastic interface in ultrasonic welded metal/fibre-reinforced polymer joints. Comput. Mater. Sci. 2010, 50, 184-190. [CrossRef]

15. Lambiase, F.; Di Ilio, A. Mechanical clinching of metal-polymer joints. J. Mater. Process. Technol. 2015, 215, 12-19. [CrossRef]

16. Golewski, P.; Sadowski, T.; Pietras, D.; Dudzik, S. The influence of aging in salt chamber on strength of aluminum-CFRP single lap joints. Mater. Today Proc. 2021, 45, 4264-4267. [CrossRef]

17. Negru, R.; Marsavina, L.; Hluscu, M. Experimental and numerical investigations on adhesively bonded joints. IOP Conf. Series Mater. Sci. Eng. 2016, 123, 012012. [CrossRef]

18. Golewski, P.; Sadowski, T. The Influence of Single Lap Geometry in Adhesive and Hybrid Joints on Their Load Carrying Capacity. Materials 2019, 12, 1884. [CrossRef]

19. Golewski, P.; Sadowski:, T. The influence of dual adhesive in single lap joints on strength and energy absorption. Mater. Today Proc. 2021, 45, 4280-4285. [CrossRef]

20. Gajewski, J.; Golewski, P.; Sadowski, T. The Use of Neural Networks in the Analysis of Dual Adhesive Single Lap Joints Subjected to Uniaxial Tensile Test. Materials 2021, 14, 419. [CrossRef] [PubMed]

21. Xu, Y.; Huettig, F.; Schille, C.; Schweizer, E.; Geis-Gerstorfer, J.; Spintzyk, S. Peel bond strength between 3D printing tray materials and elastomeric impression/adhesive systems: A laboratory study. Dent. Mater. 2020, 36, e241-e254. [CrossRef] [PubMed]

22. Khosravani, M.R.; Soltani, P.; Reinicke, T. Fracture and structural performance of adhesively bonded 3D-printed PETG single lap joints under different printing parameters. Theor. Appl. Fract. Mech. 2021, 116, 103087. [CrossRef]

23. Nash, R.J.; Li, Y. Experimental and numerical analysis of 3D printed suture joints under shearing load. Eng. Fract. Mech. 2021, 253, 107912. [CrossRef]

24. Khosravani, M.R.; Soltani, P.; Weinberg, K.; Reinicke, T. Structural integrity of adhesively bonded 3D-printed joints. Polym. Test. 2021, 100, 107262. [CrossRef]

25. Yap, Y.L.; Toh, W.; Koneru, R.; Lin, R.; Chan, K.I.; Guang, H.; Chan, W.Y.B.; Teong, S.S.; Zheng, G.; Ng, T.Y. Evaluation of structural epoxy and cyanoacrylate adhesives on jointed 3D printed polymeric materials. Int. J. Adhes. Adhes. 2020, 100, 102602. [CrossRef]

26. Li, W.; Sang, L.; Jian, X.; Wang, J. Influence of sanding and plasma treatment on shear bond strength of 3D-printed PEI, PEEK and PEEK/CF. Int. J. Adhes. Adhes. 2020, 100, 102614. [CrossRef]

27. Jucienè, M.; Dobilaite, V. Impact of climatic effects and various surfaces on the tack of adhesive tapes for building \& construction. J. Build. Eng. 2021, 42, 102825. [CrossRef]

28. Biel, A.; Alfredsson, K.S.; Carlberger, T. Adhesive Tapes; Cohesive Laws for a Soft Layer. Procedia Mater. Sci. 2014, 3, 1389-1393. [CrossRef]

29. Fufa, S.M.; Labonnote, N.; Frank, S.; Rüther, P.; Jelle, B.P. Durability evaluation of adhesive tapes for building applications. Constr. Build. Mater. 2018, 161, 528-538. [CrossRef] 
30. Liao, Z.; Hossain, M.; Yao, X.; Mehnert, M.; Steinmann, P. On thermo-viscoelastic experimental characterization and numerical modelling of VHB polymer. Int. J. Non-Linear Mech. 2020, 118, 103263. [CrossRef]

31. Zhu, Z.; Xia, Y.; Jiang, C.; Yang, Z.; Jiang, H. Investigation of zero-degree peeling behavior of visco-hyperelastic highly stretchable adhesive tape on rigid substrate. Eng. Fract. Mech. 2021, 241, 107368. [CrossRef]

32. Sadowski, T.; Nowicki, M.; Golewski, P. The influence of the use of fasteners with different stiffness in hybrid joints subjected to complex mechanical loads. Arch. Metall. Mater. 2019, 64, 1263-1268. [CrossRef]

33. Sadowski, T.; Golewski, P. Modelling and Experimental Testing of Hybrid Joints Made of: Aluminium Adherends, Adhesive Layers and Rivets for Aerospace Applications. Arch. Met. Mater. 2017, 62, 1577-1583. [CrossRef]

34. Elzaroug, M.; Kadioglu, F.; Demiral, M.; Saad, D. Experimental and numerical investigation into strength of bolted, bonded and hybrid single lap joints: Effects of adherend material type and thickness. Int. J. Adhes. Adhes. 2018, 87, 130-141. [CrossRef]

35. Li, X.; Cheng, X.; Cheng, Y.; Wang, Z.; Huang, W. Tensile properties of a composite-metal single-lap hybrid bonded/bolted joint. Chin. J. Aeronaut. 2021, 34, 629-640. [CrossRef]

36. Romanov, V.S.; Heidari-Rarani, M.; Lessard, L. A parametric study on static behavior and load sharing of multi-bolt hybrid bonded/bolted composite joints. Compos. Part B Eng. 2021, 217, 108897. [CrossRef]

37. Huang, Z.; Sugiyama, S.; Yanagimoto, J. Hybrid joining process for carbon fiber reinforced thermosetting plastic and metallic thin sheets by chemical bonding and plastic deformation. J. Mater. Process. Technol. 2013, 213, 1864-1874. [CrossRef]

38. Marques, G.; Campilho, R.; Silva, F.; Moreira, R.D.F. Adhesive selection for hybrid spot-welded/bonded single-lap joints: Experimentation and numerical analysis. Compos. Part B Eng. 2016, 84, 248-257. [CrossRef]

39. Marsavina, L.; Nurse, A.D.; Braescu, L.; Craciun, E.M. Stress singularity of symmetric free-edge joints with elasto-plastic behaviour. Comput. Mater. Sci. 2012, 52, 282-286. [CrossRef]

40. Sadowski, T.; Golewski, P. Numerical Study of the Prestressed Connectors and Their Distribution on the Strength of a Single Lap, a Double Lap and Hybrid Joints Subjected to Uniaxial Tensile Test. Arch. Met. Mater. 2013, 58, 579-585. [CrossRef] 